\title{
Three-Dimensional Upper Bound Limit Analysis on the Collapse of Shallow Soil Tunnels considering Roof Stratification and Pore Water Pressure
}

\author{
Hong-Tao Wang $\mathbb{D}^{1,2}$ Ping Liu $\mathbb{D}^{1,2}$ Chi Liu, ${ }^{3}$ Xin Zhang, ${ }^{1,2}$ Yong Yang, ${ }^{4}$ and Lu-Yao Liu ${ }^{1,2}$ \\ ${ }^{1}$ School of Civil Engineering, Shandong Jianzhu University, Jinan 250101, China \\ ${ }^{2}$ Shandong Co-Innovation Center for Disaster Prevention and Mitigation of Civil Structures, Shandong Jianzhu University, \\ Jinan 250101, China \\ ${ }^{3}$ Jinan Rail Transit Group Co., Ltd., Jinan 250101, China \\ ${ }^{4}$ Shandong Academy of Building Research, Jinan 250031, China \\ Correspondence should be addressed to Hong-Tao Wang; wanghongtao918@163.com and Ping Liu; 1215643305@qq.com
}

Received 9 April 2019; Revised 25 September 2019; Accepted 11 October 2019; Published 11 November 2019

Academic Editor: Federico Guarracino

Copyright (C) 2019 Hong-Tao Wang et al. This is an open access article distributed under the Creative Commons Attribution License, which permits unrestricted use, distribution, and reproduction in any medium, provided the original work is properly cited.

\begin{abstract}
Based on the plastic upper bound theorem, a three-dimensional kinematically admissible velocity field is constructed for the collapse of the soil masses above a shallow tunnel. In this field, this paper considers the influences of the roof stratification, pore water pressure, ground overload, and support pressure. This study deduced the upper bound solutions of the weight of the collapsed soil masses and the corresponding collapse surfaces by utilizing the nonlinear failure criterion, associated flow rule, and variation principle. Furthermore, we verified the validity of the proposed method in this paper by comparing this research with the existing work and numerical simulation results. This study obtains the influence laws of varying parameters on the area and weight of the collapsed soil masses. The results reveal that the area and weight of the collapsed soil masses increase with increasing support pressure and soil cohesion, but decrease with increasing thickness of the upper soil layer, nonlinear coefficient, pore water pressure, and ground overload. Among them, the roof stratification, pore water pressure, soil cohesion, and nonlinear coefficient have a significant influence on tunnel collapse, which should be given special consideration in engineering design.
\end{abstract}

\section{Introduction}

With the rapid development of the world economy and the wide application of advanced technology, the transportation industry has developed rapidly in recent years. The tunnel, due to its superiority, is widely used in underground engineering such as subways, highways, railways, and municipal engineering. Most tunnels are classified as rock tunnels and soil tunnels according to the strata they pass through or deep tunnels and shallow tunnels according to the burial depth. Shallow soil tunnels, due to thin overburden, low soil strength, and poor self-stability are very prone to ground collapse accidents under the influences of excavation disturbance, groundwater, and ground overload (as shown in Figure 1). These accidents are a typical problem in stability control for surrounding soil masses of such tunnels $[1,2]$.
Research related to the failure characteristics and stability control of shallow tunnels has become the focus of many scholars. Among various research methods, the upper bound method is a classical theoretical method. By constructing a kinematically admissible velocity field for tunnel failure, this method aims to resolve these failure problems by using the principle of balance between the internal energy dissipation power and external force power, which can effectively simplify complex engineering problems and achieve practical solutions, making it widely favored by scholars. For example, Leca and Dormieux [3], Lee et al. [4], Augarde et al. [5], Zhang et al. [6], and Khezri et al. [7] investigated the two- or three-dimensional stability of the tunnel face based on upper or lower bound theorems. These studies considered the soil masses around the tunnel as traditional Mohr-Coulomb material. Fraldi and Guarracino $[8,9]$ introduced the nonlinear Hoek-Brown failure 


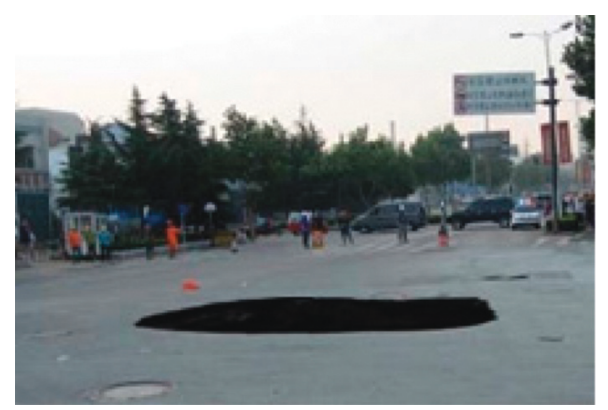

(a)

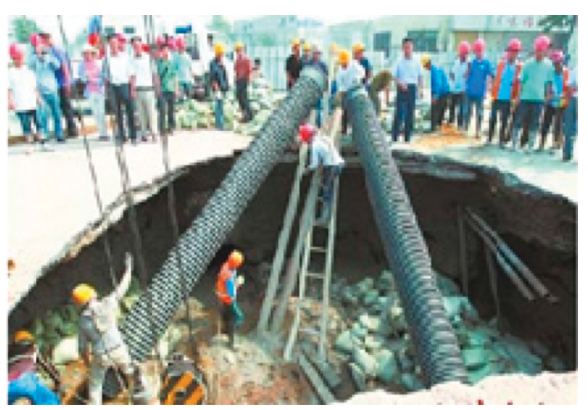

(b)

Figure 1: Pavement collapse caused by subway tunnel construction in Qingdao, China [2].

criterion into the limit analysis of tunnel collapse, obtained the upper bound solution of the collapse surface, and verified the validity of the upper bound method by using the numerical simulation technology. Also, Fraldi et al. [10] proposed a general characterization of tunnels depth based on the profundity of the excavation and on the variability of the rock mass parameters, and compared the stability of shallow tunnels, intermediate tunnels, and deep tunnels. On this basis, Yang et al. [11, 12] and Huang et al. [13] focused on the circular and rectangular shallow tunnels and constructed the two-dimensional roof failure mechanisms. Then they obtained the upper bound solutions of the roof collapse surfaces of shallow tunnels with varying crosssection shapes and analyzed the influence laws of varying parameters on the collapse area. Huang and Yang [14] also introduced the effect of pore water into the collapse mechanism of a circular tunnel. Zhang et al. [15] compared the proposed collapse mechanism with the results of model tests. Wang et al. [16] proposed two kinds of collapse mechanisms for a shallow tunnel by considering the influence of the changing groundwater table and obtained the collapse surface equation and collapse area of the surrounding rock masses. Lyu and Zeng [17] investigated the collapse of shallow tunnels in inclined rock stratum. It should be noted that the Hoek-Brown failure criterion employed in the above research works may be more suitable for rock tunnels. As for soil tunnels, a failure criterion for the soil masses may be more suitable. Meanwhile, the documents mentioned above presumed that the tunnel collapse was a two-dimensional problem. However, in practical engineering, tunnel collapse should be a typical three-dimensional problem, as shown in Figure 1. For example, Yang and Huang [18], Huang et al. [19], Qin et al. [20], Soubra et al. [21], and Guan et al. [22] employed the three-dimensional mechanisms to investigate the failure characteristic of tunnels or cavities. In addition, influenced by the sedimentary history of the strata, the strata also show prominent stratification characteristics. Unfortunately, at present, there is still a lack of relevant research on the three-dimensional collapse mechanism of shallow soil tunnels in the layered strata. Other factors like the pore water pressure and ground overload also have a direct impact on tunnel failure and stability. Yang et al. [23-25] as well as Qin et al. [26-29] once incorporated the nonhomogeneous and stratified characteristics of the strata into their analysis of the roof collapse, which may provide a good theoretical basis for this paper; however, their research is only applicable to deep tunnels.
It is a crucial issue to correctly determine the area, weight of the collapsed soil masses, and the required support pressure to ensure the long-term safety of shallow soil tunnels. In this paper, we take the shallow soil tunnel in layered strata as the research object and construct a threedimensional kinematically admissible velocity field for roof collapse. We consider the joint influences of roof stratification, pore water pressure, ground overload, and support pressure. According to the nonlinear Mohr-Coulomb failure criterion, associated flow rule, and upper bound theorem, we deduce the analytical solutions of the weight of the collapsed soil masses and the corresponding collapse surfaces in the three-dimensional model. The research in this paper may provide theoretical guidance for tunnel support design and collapse warning in similar conditions.

\section{Nonlinear Mohr-Coulomb Failure Criterion}

At present, most researchers study geotechnical stability problems based on the linear Mohr-Coulomb (MC) failure criterion. However, the results of abundant indoor tests [30-32] show that the geomaterials show visible nonlinear characteristics in failure; that is, the strength envelope curves of the geomaterials should be nonlinear. In particular, the traditional MC failure criterion rarely accurately describes the mechanical properties of the geomaterials in the tensilestress zone, low-stress zone, and high-stress zone. To solve this problem, Yang [33] introduced a nonlinear MC failure criterion into the limit analysis theory and applied it widely in the stability analysis of the slopes, foundations, and tunnels. Accordingly, we also adopt this criterion in this paper to describe the failure characteristics of the soil masses around the tunnel. The expression is as follows:

$$
\tau_{n}=c_{0}\left(1+\frac{\sigma_{n}}{\sigma_{t}}\right)^{1 / m},
$$

where $\tau_{n}$ and $\sigma_{n}$ refer to the shear stress and normal stress, respectively, on the failure surface; $c_{0}$ is the initial cohesion of the soil mass; $\sigma_{t}$ is the tensile strength of the soil mass; and $m$ is the nonlinear coefficient related to soil properties. When $m=1$ and $c_{0} / \sigma_{t}=\tan \varphi$ ( $\varphi$ is the internal friction angle), equation (1) can be converted into the expression of the traditional MC failure criterion. 


\section{Three-Dimensional Upper Bound Limit Analysis on the Collapse of Shallow Soil Tunnels}

3.1. Three-Dimensional Collapse Mechanism in Layered Strata. Once the support types are improper or the support pressure is insufficient, the shallow tunnels, due to thin overburden, low soil strength, and poor self-stability are very prone to collapse under the unfavorable influences such as excavation disturbance, groundwater, and ground overload. Moreover, as can be seen in Figure 1, we may find that the tunnel collapse area is three-dimensional in space, and the failure profile on the ground surface is approximately circular. Given this and by reference to the current theoretical and experimental research works [8-29], we construct a three-dimensional axisymmetric collapse mechanism for shallow soil tunnels in layered strata in the ultimate state, as shown in Figure 2. In this mechanism, we consider the roof stratification characteristics and the influence of pore water pressure simultaneously.

In Figure 2, the burial depth of the tunnel is $H$. A total of $n$ soil layers are included from the ground surface to the tunnel vault, with the height of each layer ranging from $h_{1}$, $h_{2}$, to $h_{n}$. The collapsed area of the lower soil layer is larger than that of the upper soil layer. The soil masses within the collapse area are an axisymmetric spatial body around the $y$-axis and move downward at velocity $v$. Meanwhile, the tunnel collapse is also subjected to the effects of ground overload $\sigma_{s}$, support pressure $q$, and pore water pressure. The collapse surface is composed of $n$ segments. In soil layer $i$, the expression of the collapse surface is $f_{i}(x, z)$; the corresponding curve expression in plane xoy is $f_{i}(x)$; and the fracture width is $l_{i}$. Besides, the roof profile is assumed to be a plane and the corresponding expression in plane $x o y$ is $g(x)=H$. We regarded the pore water pressure within the strata as the external force acting on soil particles, and the specific calculation process can refer to the proposed method by Viratjandr and Michalowski [34].

3.2. Internal Energy Dissipation Power. The soil masses in the collapse area are assumed to be an ideal rigid-plastic material, and the plastic failure only occurs at the detaching surfaces while the tunnel collapses. Meanwhile, the failure of the soil masses complies with the associated flow rule; that is, the plastic potential surface coincides with the yield surface. Therefore, if the failure of tunnel soil masses meets the nonlinear MC failure criterion, the plastic potential function $Q$ can be expressed by the yield function $F$ as follows:

$$
Q=F=\tau_{n}-c_{0}\left(1+\frac{\sigma_{n}}{\sigma_{t}}\right)^{1 / m} \text {. }
$$

Potential theory $[35,36]$ is a commonly used theoretical method in elastic and plastic mechanics. The plastic potential theory can be expressed as follows:

$$
\dot{\varepsilon}_{i j}=\dot{\lambda} \frac{\partial Q}{\partial \sigma_{i j}},
$$

where $\sigma_{i j}$ is the stress tensor; $\dot{\varepsilon}_{i j}$ is the plastic strain rate tensor; $\dot{\lambda}$ is a plastic constant; and $Q$ is the plastic potential function.

In soil layer $i$, the collapse surface is regarded as a velocity discontinuity surface of a certain thickness $w_{i}$ $(i=1,2,3 \ldots, n)$. The plastic strain rate at this surface can be obtained as follows by substituting equation (2) into equation (3):

$$
\left\{\begin{array}{l}
\dot{\varepsilon}_{n i}=-\dot{\lambda}_{i}\left(m_{i} \sigma_{t i}\right)^{-1} c_{0 i}\left(1+\frac{\sigma_{n i}}{\sigma_{t i}}\right)^{\left(1-m_{i}\right) / m_{i}}, \\
\dot{\gamma}_{n i}=\dot{\lambda}_{i},
\end{array}\right.
$$

where $m_{i}, c_{0 i}$, and $\sigma_{t i}$ refer to the nonlinear coefficient, cohesion, and tensile strength of the soil mass in soil layer $i$, respectively. In combination with the geometric relationships in Figure 2, the plastic strain rate at the collapse surface can also be expressed as follows:

$$
\left\{\begin{array}{l}
\dot{\varepsilon}_{n i}=\frac{v}{w_{i}}\left[1+f_{i}^{\prime}(x)^{2}\right]^{-1 / 2} \\
\dot{\gamma}_{n i}=-\frac{v}{w_{i}} f_{i}^{\prime}(x)\left[1+f_{i}^{\prime}(x)^{2}\right]^{-1 / 2}
\end{array}\right.
$$

The plastic strain rate in equation (4) is equated with that in equation (5), and the plastic constant in equation (3) can be obtained as follows:

$$
\dot{\lambda}_{i}=-\frac{v}{w_{i}} f_{i}^{\prime}(x)\left[1+f_{i}^{\prime}(x)^{2}\right]^{-1 / 2} .
$$

Meanwhile, the normal stress on the velocity discontinuity surface in soil layer $i$ can be expressed as follows:

$$
\sigma_{n i}=-\sigma_{t i}+\sigma_{t i}\left[\left(m_{i} \sigma_{t i}\right)^{-1} c_{0 i} f_{i}^{\prime}(x)\right]^{m_{i} /\left(m_{i}-1\right)} .
$$

In soil layer $i$, since the soil mass is an ideal rigid-plastic material, we may assume the soil mass within the collapse area and the surrounding static soil mass is rigid. Then, the internal energy dissipation only occurs on the velocity discontinuity surface. The internal energy dissipation rate per unit volume on this surface should be equal to the sum of the normal stress and tangential stress multiplied by their corresponding plastic strain rates at any point. According to equations (1), (5), and (7), it can be expressed as follows:

$$
\begin{aligned}
\dot{D}_{i}= & \sigma_{n i} \dot{\varepsilon}_{n i}+\tau_{n i} \dot{\gamma}_{n i} \\
= & \left\{\left(1-m_{i}\right)\left[m_{i}^{-1} c_{0 i} f_{i}^{\prime}(x)\right]^{m_{i} /\left(m_{i}-1\right)} \sigma_{t i}^{1 /\left(1-m_{i}\right)}-\sigma_{t i}\right\} \\
& \cdot \frac{v}{w_{i}}\left[1+f_{i}^{\prime}(x)^{2}\right]^{-1 / 2} .
\end{aligned}
$$

According to the geometric relationships in Figure 2, equation (8) is integrated in $\left[l_{i}, l_{i+1}\right](i=1,2,3, \ldots, n)$ along the velocity discontinuity surface, and the obtained integrals are added along $n$ layers. Thus, the internal energy dissipation rate corresponding to the whole three-dimensional mechanism can be obtained as follows: 


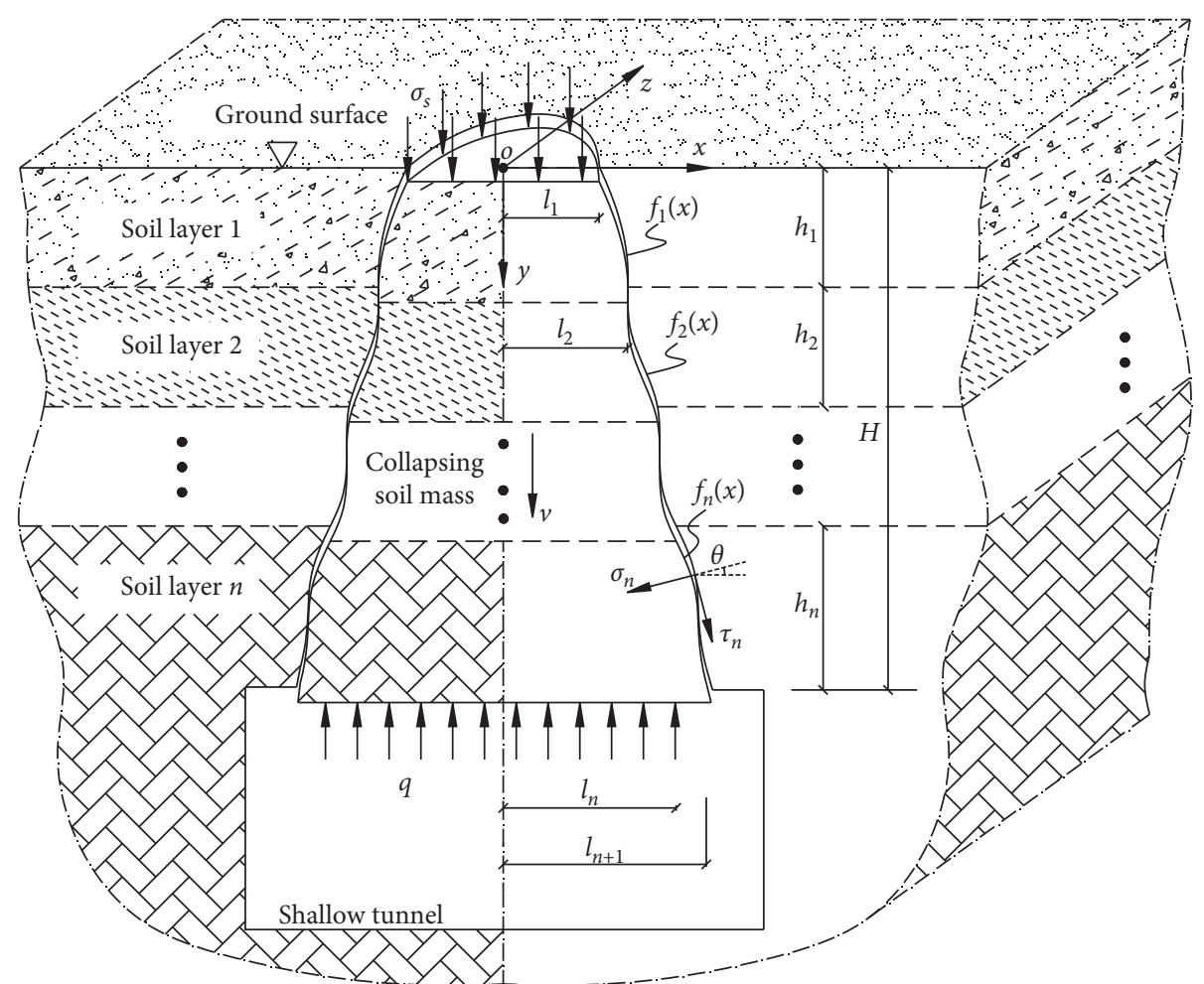

Figure 2: Three-dimensional collapse mechanism of the shallow soil tunnel in layered strata.

$$
\begin{aligned}
W_{D}= & 2 \pi \sum_{i=1}^{n} \int_{l_{i}}^{l_{i+1}}\left\{\left(1-m_{i}\right)\left[m_{i}^{-1} c_{0 i} f_{i}^{\prime}(x)\right]^{m_{i} /\left(m_{i}-1\right)} \sigma_{t i}^{1 /\left(1-m_{i}\right)}\right. \\
& \left.\cdot x-\sigma_{t i} x\right\} \mathrm{d} x \cdot v .
\end{aligned}
$$

3.3. External Force Power. In addition to the internal energy dissipation in Figure 2, the external force power is also produced on the collapsed soil masses under the action of external forces such as self-weight, support pressure, ground overload, and pore water pressure. In particular, the gravity power of the collapsed soil masses above the tunnel can be expressed as follows:

$$
W_{\gamma}=\left\{\sum_{i=1}^{n} \pi \gamma_{i} h_{i} l_{i}^{2}+2 \pi \sum_{i=1}^{n} \int_{l_{i}}^{l_{i+1}} \gamma_{i}\left[\sum_{j=1}^{i} h_{j} x-x f_{i}(x)\right] \mathrm{d} x\right\} \nu,
$$

where $\gamma_{i}$ is the unit weight in any soil layer $i$ and $h_{i}$ is the thickness of any soil layer $i$. follows:

The power of support pressure $q$ can be expressed as

$$
W_{q}=-\pi q l_{n+1}^{2} v
$$
follows:

The power of ground overload $\sigma_{s}$ can be expressed as

$$
W_{\sigma_{s}}=\pi \sigma_{s} l_{1}^{2} v
$$

The power of pore water pressure can be expressed as follows:

$$
W_{u}=-2 \pi \sum_{i=1}^{n} \int_{l_{i}}^{l_{i+1}} \gamma_{u i} \gamma_{i} x f_{i}(x) \mathrm{d} x \cdot v,
$$

where $\gamma_{u i}$ is the pore water pressure coefficient in any soil layer $i$.

3.4. Determination of Three-Dimensional Collapse Mode. According to the internal energy dissipation rate obtained from equation (9) and the external force power obtained from equations (10)-(13), an objective function $\xi$ can be constructed. Specifically, its value represents the total energy loss generated in the whole mechanism in Figure 2, and it can be expressed as follows:

$$
\begin{aligned}
\xi= & W_{D}+W_{r}+W_{q}+W_{\sigma_{s}}+W_{u} \\
= & \left\{2 \pi \sum_{i=1}^{n} \int_{l_{i}}^{l_{i+1}} \Lambda_{i}\left[x, f_{i}(x), f_{i}^{\prime}(x)\right] \mathrm{d} x+\sum_{i=1}^{n} \pi \gamma_{i} h_{i} l_{i}^{2}-\pi q l_{n+1}^{2}\right. \\
& \left.+\pi \sigma_{s} l_{1}^{2}\right\} v,
\end{aligned}
$$

where $\Lambda_{i}\left[x, f_{i}(x), f_{i}^{\prime}(x)\right]$ is

$$
\begin{aligned}
& \Lambda_{i}\left[x, f_{i}(x), f_{i}^{\prime}(x)\right] \\
& =\left(1-m_{i}\right) x\left[m_{i}^{-1} c_{0 i} f_{i}^{\prime}(x)\right]^{m_{i} /\left(m_{i}-1\right)} \sigma_{t i}^{1 /\left(1-m_{i}\right)}-\sigma_{t i} x \\
& \quad+\gamma_{i} \sum_{j=1}^{i} h_{j} x-\left(\gamma_{u i}+1\right) \gamma_{i} x f_{i}(x) .
\end{aligned}
$$


In equation (14), the objective function $\xi$ is a functional of $f_{i}(x)$ corresponding to all potential collapse curves. In particular, the curve $f_{i}(x)$ corresponding to the real collapse mechanism should minimize the energy loss generated by the whole failure mechanism. Therefore, this is a typical variation problem. The following Euler-Lagrange equation can be utilized to solve this problem:

$$
\frac{\partial \Lambda}{\partial f_{i}(x)}-\frac{\partial}{\partial x}\left(\frac{\partial \Lambda}{\partial f_{i}^{\prime}(x)}\right)=0 .
$$

Equation (15) is substituted into equation (16) to obtain

$$
\begin{aligned}
& -\left(\gamma_{u i}+1\right) \gamma_{i} x+m_{i}\left(m_{i}^{-1} c_{0 i}\right)^{m_{i} /\left(m_{i}-1\right)} \sigma_{t i}^{1 /\left(1-m_{i}\right)}\left[f_{i}^{\prime}(x)\right]^{1 /\left(m_{i}-1\right)} \\
& \quad+\frac{m_{i}}{m_{i}-1} x\left(m_{i}^{-1} c_{0 i}\right)^{m_{i} /\left(m_{i}-1\right)} \\
& \sigma_{t i}^{1 /\left(1-m_{i}\right)}\left[f_{i}^{\prime}(x)\right]^{\left(2-m_{i}\right) /\left(m_{i}-1\right)} f_{i}^{\prime \prime}(x)=0 .
\end{aligned}
$$

Then, $f_{i}^{\prime}(x)$ can be obtained by integrating both sides of equation (17) as follows:

$$
f_{i}^{\prime}(x)=m_{i} c_{0 i}^{-m_{i}} \sigma_{t i}\left[\frac{1}{2}\left(1+\gamma_{u i}\right) \gamma_{i}\right]^{m_{i}-1}\left[\frac{2 A_{i}}{\left(1+\gamma_{u i}\right) \gamma_{i} x}+x\right]^{m_{i}-1},
$$

where $A_{i}$ is an undetermined constant for integration. The integral solving of equation (18) is very complex, and it is challenging to obtain its analytical solution. However, we note that the collapse process of the soil masses at the tunnel roof should be progressive. To be specific, the collapse starts from the lower soil layer and penetrates to the upper layer when the lower completely fractures. Similarly, the fracture of the soil mass inside a soil layer $i$ also develops from bottom to top. When the internal fracture of the soil layer is formed in the lower part before penetrating the upper part, the failure of the soil mass is approximately identical with that in the homogeneous formation. Moreover, the collapse area of this layer is an axisymmetric body around the $y$-axis. Thus, according to the collapse characteristics in the homogeneous formation and the symmetry of the proposed mechanism in Figure 2, we may assume the collapse curve $f_{i}(x)$ to meet $\left.f_{i}^{\prime}(x)\right|_{x=0}=0$ at point $x=0$ by referring to the treatment method of Yang and Yao [23]. Then, $A_{i}=0$ in equation (18) can be obtained, and equation (18) can be simplified as follows:

$$
f_{i}^{\prime}(x)=m_{i} \delta_{i} x^{m_{i}-1},
$$

where $\delta_{i}=c_{0 i}^{-m_{i}} \sigma_{t i}\left[(1 / 2)\left(1+\gamma_{u i}\right) \gamma_{i}\right]^{m_{i}-1}$.

The following can be obtained by integrating equation (19):

$$
f_{i}(x)=\delta_{i} x^{m_{i}}+B_{i},
$$

where $B_{i}$ is another undetermined constant, whose value can be solved according to the boundary conditions in Figure 2 .

Accordingly, the expression of the three-dimensional axisymmetric collapse surface in Figure 2 can be obtained from equation (20) as follows:

$$
y=f_{i}(x, z)=\delta_{i}\left(x^{2}+z^{2}\right)^{m_{i} / 2}+B_{i} .
$$

The expression of $\Lambda_{i}\left[x, f_{i}(x), f_{i}^{\prime}(x)\right]$ can be obtained after substituting equations (19) and (20) into equation (15):

$$
\begin{aligned}
\Lambda_{i}\left[x, f_{i}(x), f_{i}^{\prime}(x)\right]= & -\frac{\delta_{i}}{2}\left(m_{i}+1\right)\left(1+\gamma_{u i}\right) \gamma_{i} x^{1+m_{i}}-\sigma_{t i} x \\
& +\gamma_{i} x \sum_{j=1}^{i} h_{j}-\left(1+\gamma_{u i}\right) \gamma_{i} x B_{i} .
\end{aligned}
$$

Furthermore, the following conditional equations can be built based on the geometric relationships in Figure 2:

$$
\left\{\begin{array}{l}
\left.f_{1}(x)\right|_{x=l_{1}}=0, \\
\left.f_{1}(x)\right|_{x=l_{2}}=\left.f_{2}(x)\right|_{x=l_{2}}=h_{1}, \\
\left.f_{2}(x)\right|_{x=l_{3}}=\left.f_{3}(x)\right|_{x=l_{3}}=h_{1}+h_{2}, \\
\cdots \\
\left.f_{n-1}(x)\right|_{x=l_{n}}=\left.f_{n}(x)\right|_{x=l_{n}}=h_{1}+h_{2}+\cdots+h_{n-1}, \\
\left.f_{n}(x)\right|_{x=l_{n+1}}=H .
\end{array}\right.
$$

Then equation (20) is substituted into equation (23) to obtain the following equations:

$$
\left\{\begin{array}{l}
\delta_{1} l_{1}^{m_{1}}+B_{1}=0 \\
\delta_{1} l_{2}^{m_{1}}+B_{1}=\delta_{2} l_{2}^{m_{2}}+B_{2}=h_{1}, \\
\delta_{2} l_{3}^{m_{2}}+B_{2}=\delta_{3} l_{3}^{m_{3}}+B_{3}=h_{1}+h_{2}, \\
\cdots \\
\delta_{n-1} l_{n-1}^{m_{n-1}}+B_{n-1}=\delta_{n} l_{n}^{m_{n}}+B_{n}=h_{1}+h_{2}+\cdots+h_{n-1}, \\
\delta_{n} l_{n+1}^{m_{n}}+B_{n}=H .
\end{array}\right.
$$

The undetermined constant $B_{i}$ can be obtained by simultaneous solving as follows:

$$
\left\{\begin{array}{l}
B_{1}=-\delta_{1} l_{1}^{m_{1}}, \\
B_{2}=h_{1}-\delta_{2} l_{2}^{m_{2}}, \\
B_{3}=h_{1}+h_{2}-\delta_{3} l_{3}^{m_{3}}, \\
\cdots \\
B_{n}=h_{1}+h_{2}+\cdots+h_{n-1}-\delta_{n} l_{n}^{m_{n}} .
\end{array}\right.
$$

Meanwhile, the following equations can also be obtained by simplifying equation (24):

$$
\left\{\begin{array}{l}
\delta_{1} l_{2}^{m_{1}}-\delta_{1} l_{1}^{m_{1}}=h_{1} \\
\delta_{2} l_{3}^{m_{2}}-\delta_{2} l_{2}^{m_{2}}=h_{2} \\
\delta_{3} l_{4}^{m_{3}}-\delta_{3} l_{3}^{m_{3}}=h_{3} \\
\cdots \\
\delta_{n-1} l_{n-1}^{m_{n-1}}-\delta_{n-1} l_{n-1}^{m_{n-1}}=h_{n-1} \\
\delta_{n} l_{n+1}^{m_{n}}-\delta_{n} l_{n}^{m_{n}}=h_{n}
\end{array}\right.
$$


In order to further determine the collapse area of the soil masses above the shallow tunnel, it is necessary to determine $n+1$ unknown parameters $l_{1}-l_{n+1}$, but equation (26) contains only $n$ equations. To solve this problem, we used the upper bound theorem to make the internal energy dissipation rate equal to the external force power; that is, the total energy loss $\xi$ generated in the mechanism in Figure 2 is equal to zero. Then, the following equation can be obtained after substituting equation (22) into equation (14):

$$
\begin{aligned}
\sum_{i=1}^{n}\{ & -\frac{\left(m_{i}+1\right) \pi}{2+m_{i}} \delta_{i}\left(1+\gamma_{u i}\right) \gamma_{i}\left(l_{i+1}^{2+m_{i}}-l_{i}^{2+m_{i}}\right) \\
& \left.-\pi\left[\sigma_{t i}-\gamma_{i} \sum_{j=1}^{i} h_{j}+\left(1+\gamma_{u i}\right) \gamma_{i} B_{i}\right]\left(l_{i+1}^{2}-l_{i}^{2}\right)+\pi \gamma_{i} h_{i} l_{i}^{2}\right\} v \\
& -\pi q l_{n+1}^{2} v+\pi \sigma_{s} l_{1}^{2} v=0 .
\end{aligned}
$$

According to this, the fracture width $l_{1}-l_{n+1}$ of the collapsed soil masses can be obtained by simultaneously solving equations (26) and (27). Then, the roof collapse area of the shallow soil tunnel in layered strata can be determined. Accordingly, the weight of the collapsed soil masses can be expressed as follows:

$$
\begin{aligned}
G_{\gamma}= & \sum_{i=1}^{n}\left[\pi \gamma_{i}\left(\sum_{j=1}^{i} h_{j}-B_{i}\right)\left(l_{i+1}^{2}-l_{i}^{2}\right)-2 \pi\left(2+m_{i}\right)^{-1}\right. \\
& \left.\cdot \gamma_{i} \delta_{i}\left(l_{i+1}^{2+m_{i}}-l_{i}^{2+m_{i}}\right)+\pi \gamma_{i} h_{i} l_{i}^{2}\right] .
\end{aligned}
$$

\section{Discussion and Analysis}

4.1. Comparison with Existing Research. In combination with the existing research results, we determined that there must be a critical burial depth $H_{c}$ for deep and shallow tunnels. When the tunnel burial depth $H<H_{c}$, the failure of the soil masses at the roof will penetrate the ground surface, which is the collapse mechanism proposed in this paper. On the contrary, when the burial depth $H>H_{c}$, the failure of the soil masses will not penetrate the ground surface and the collapse arch may be formed inside the roof to resist the surrounding rock pressure from the soil masses above, thus presenting failure characteristics of the deep tunnel. For example, Yang and Yao [23] once adopted the nonlinear MC failure criterion to put forward the three-dimensional collapse mechanism of deep soil tunnels and investigated the influence laws of varying parameters on the collapse area of the tunnel roof. Accordingly, in order to verify the validity of the proposed method in this paper, we conduct the following comparison in this section based on the collapse characteristics of deep and shallow tunnels and Yang and Yao [23]. Specifically, as shown in Figure 2, when the fracture width at the top of the collapsed soil masses is equal to zero, both sides of the collapsed surfaces intersect, thus forming a collapse arch within the roof surrounding soils. Then, we can convert the mechanism proposed in this paper into that put forward by Yang and Yao [23]. Further, Table 1 lists the corresponding calculation results of the two mechanisms. As can be seen from Table 1 , when $l_{1}=0$, the calculation results in this paper are the same as those in Yang and Yao [23] and the corresponding two collapse mechanisms are consistent, thus verifying the validity of the proposed method in this paper.

4.2. Comparison with Numerical Simulation Results. In this section, we employ the numerical simulation technique to further evaluate the validity of the proposed method in this paper. We construct the numerical model for a shallow rectangular tunnel in the commercial software program FLAC ${ }^{3 \mathrm{D}}$, as shown in Figure 3. The tunnel has a size of $5 \mathrm{~m} \times 3 \mathrm{~m}$ and a buried depth of $5 \mathrm{~m}$. The tunnel roof is stratified, and we consider four cases for 2-5 roof soil layers, respectively. However, the nonlinear MC failure criterion utilized in this paper is not embedded in the FLAC ${ }^{3 \mathrm{D}}$, which may bring difficulties to the comparison between the upper bound solution and the numerical simulation results. To solve this problem, we employ the equivalent linear MC parameters in the numerical simulation process. Specifically, we set the nonlinear coefficient $m$ in equation (1) equal to 1 ; then, we converted the nonlinear $\mathrm{MC}$ failure criterion into the traditional MC failure criterion. Table 2 lists the equivalent strength parameters when the tunnel roof is comprised of five soil layers. In the other three cases, the first set of parameters in Table 2 specifies the soil layers with an odd number and the second set of parameters in Table 2 specifies the soil layers with an even number.

After the equilibrium of initial geostatic stress in the numerical models, the tunnel is excavated. Figure 4 lists the contour of vertical displacement within the tunnel roof for varying stratification numbers. We show that the collapse displacement of the soils at the central area of the tunnel roof is maximum. The shape of the contour lines is approximately consistent with that of the proposed analytical approach in this paper. Also, the results of the upper bound solution can be effectively used to delineate the roof collapse region.

\subsection{Effects of Roof Stratification and Pore Water Pressure on} the Collapse Area. In order to investigate the effects of roof stratification and pore water pressure on the collapse area, we take a rectangular tunnel with $2-5$ roof soil layers as an example for discussion in this section. The tunnel burial depth is $5 \mathrm{~m}$. The ground overload is $40 \mathrm{kPa}$. Figures 5 and 6 list the collapse surfaces for varying roof stratification numbers, pore water pressure coefficients, and thicknesses of soil layers. The adopted parameters in Layer 1, 3, 5 are as follows: $\sigma_{s}=400 \mathrm{kPa}$, $m_{1}=2.6, c_{01}=30 \mathrm{kPa}, \sigma_{t 1}=50 \mathrm{kPa}$, and $\gamma_{1}=18 \mathrm{kN} / \mathrm{m}^{3}$. The adopted parameters in Layer 2, 4 are as follows: $m_{2}=2.4$, $c_{02}=40 \mathrm{kPa}, \sigma_{t 2}=60 \mathrm{kPa}$, and $\gamma_{2}=20 \mathrm{kN} / \mathrm{m}^{3}$.

As can be seen from Figures 5 and 6, the roof stratification and pore water pressure have a significant influence on the roof collapse area above the tunnel, which should not be neglected in tunnel support design. Specifically, the collapse area decreases with increasing pore water pressure coefficient, which is consistent with the influence laws in Yang and Yao [23]. When the tunnel roof is comprised of two layers, the collapse area increases with increasing thickness of the lower soil layer. 
TABLE 1: Comparison of calculation results.

\begin{tabular}{|c|c|c|c|c|c|c|c|c|c|c|c|c|c|}
\hline \multirow[b]{2}{*}{$m_{1}$} & \multirow[b]{2}{*}{$m_{2}$} & \multirow[b]{2}{*}{$c_{01}(\mathrm{kPa})$} & \multirow[b]{2}{*}{$c_{02}(\mathrm{kPa})$} & \multirow[b]{2}{*}{$\sigma_{t 1}(\mathrm{kPa})$} & \multirow[b]{2}{*}{$\sigma_{t 2}(\mathrm{kPa})$} & \multirow[b]{2}{*}{$\gamma_{1}\left(\mathrm{kN} / \mathrm{m}^{3}\right)$} & \multirow[b]{2}{*}{$\gamma_{2}\left(\mathrm{kN} / \mathrm{m}^{3}\right)$} & \multicolumn{3}{|c|}{ Reference [23] (m) } & \multicolumn{3}{|c|}{ This paper $(\mathrm{m})$} \\
\hline & & & & & & & & $l_{2}$ & $l_{3}$ & $H$ & $l_{2}$ & $l_{3}$ & $H$ \\
\hline 1.8 & 1.6 & 35 & 50 & 45 & 60 & 17 & 21 & 4.5130 & 6.4319 & 10.2440 & 4.5130 & 6.4319 & 10.2440 \\
\hline 1.5 & 1.5 & 10 & 50 & 20 & 60 & 20 & 20 & 2.8224 & 5.2982 & 13.4833 & 2.8224 & 5.2982 & 13.4833 \\
\hline 1.7 & 1.5 & 45 & 55 & 60 & 70 & 20 & 21 & 5.2081 & 7.1400 & 11.6921 & 5.2081 & 7.1400 & 11.6921 \\
\hline 1.6 & 1.4 & 30 & 40 & 50 & 60 & 18 & 20 & 3.6839 & 5.4900 & 10.5195 & 3.6839 & 5.4900 & 10.5195 \\
\hline 1.4 & 1.6 & 40 & 30 & 60 & 50 & 20 & 18 & 3.9801 & 5.2176 & 9.9583 & 3.9801 & 5.2176 & 9.9583 \\
\hline
\end{tabular}

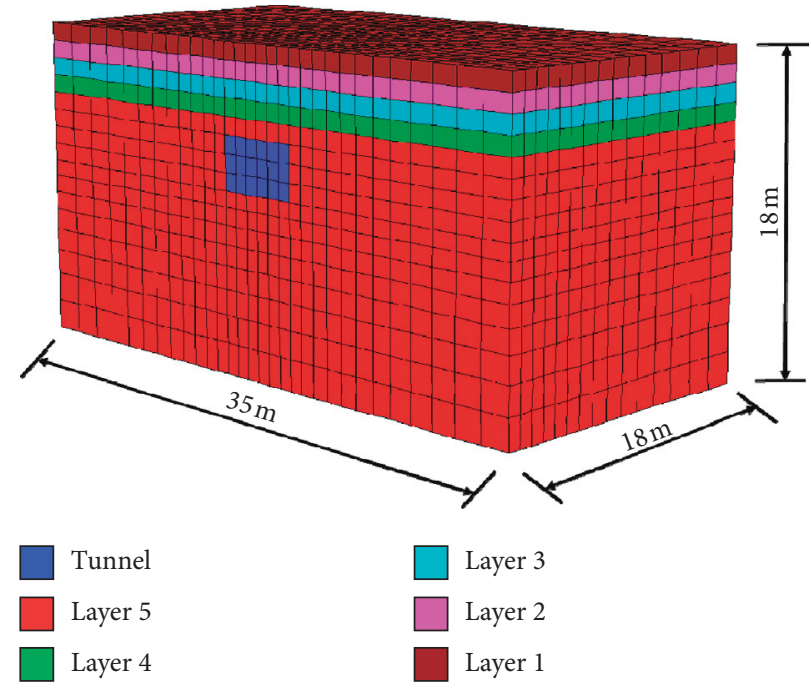

Figure 3: Numerical model for a shallow tunnel.

TABLE 2: The strength parameters of roof soil layers.

\begin{tabular}{lcc}
\hline No. & $\begin{array}{c}\text { The nonlinear MC parameters in upper bound limit } \\
\text { analysis }\end{array}$ & The equivalent MC model parameters in FLAC $^{3 \mathrm{D}}$ \\
\hline & $m_{1}=1$ & $c_{1}=15 \mathrm{kPa}$ \\
$c_{01}=15 \mathrm{kPa}$ & $\varphi_{1}=13^{\circ}$ \\
$\sigma_{t 1}=65 \mathrm{kPa}$ & $\gamma_{1}=21 \mathrm{kN} / \mathrm{m}^{3}$ \\
& $\gamma_{1}=21 \mathrm{kN} / \mathrm{m}^{3}$ & \\
& $m_{2}=1$ & $c_{2}=25 \mathrm{kPa}$ \\
$c_{02}=25 \mathrm{kPa}$ & $\varphi_{2}=16^{\circ}$ \\
& $\sigma_{t 1}=85 \mathrm{kPa}$ & $\gamma_{2}=23 \mathrm{kN} / \mathrm{m}^{3}$ \\
\hline
\end{tabular}
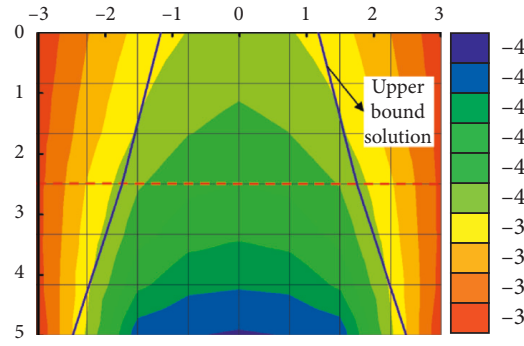

$-4.8254 e-002$ to $-4.8000 e-002$ $4.8000 e-002$ to $-4.6000 e-002$ $-4.6000 e-002$ to $-4.4000 e-002$ $-4.4000 e-002$ to $-4.2000 e-002$ $-4.2000 e-002$ to $-4.0000 e-002$ $-4.0000 e-002$ to $-3.8000 e-002$ $-3.8000 e-002$ to $-3.6000 e-002$ $-3.6000 e-002$ to $-3.4000 e-002$ $-3.4000 e-002$ to $-3.2000 e-002$ $-3.2000 e-002$ to $-3.0246 e-002$

(a)

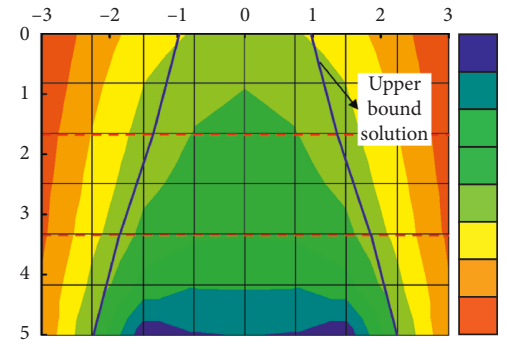

$9.3383 e-002$ to $-9.0000 e-002$ $-9.0000 e-002$ to $-8.5000 e-002$ $-8.5000 e-002$ to $-8.0000 e-002$ $-8.0000 e-002$ to $-7.5000 e-002$ $-7.5000 e-002$ to $-7.0000 e-002$ $-7.0000 e-002$ to $-6.5000 e-002$ $-6.5000 e-002$ to $-6.0000 e-002$ $-6.0000 e-002$ to $-5.5314 e-002$

(b)

FIGURE 4: Continued. 


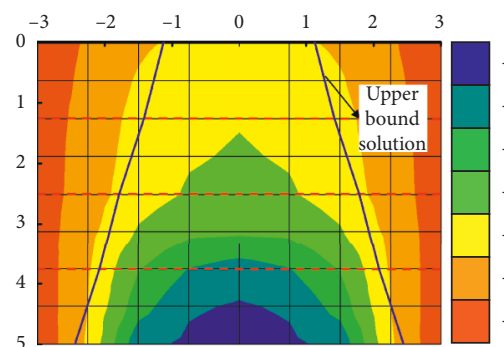

(c)

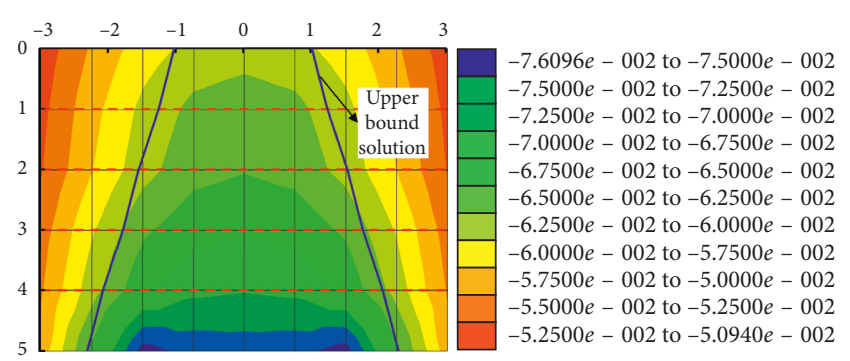

(d)

FIGURE 4: Contour of vertical displacement for varying roof stratification numbers: (a) two layers; (b) three layers; (c) four layers; (d) five layers.

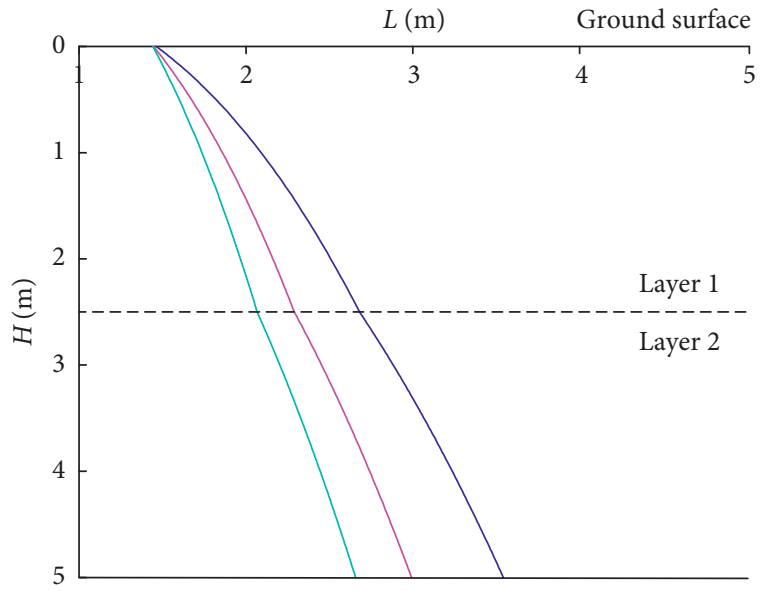

$$
\begin{aligned}
& -r_{u 1}=0, r_{u 2}=0.1 \\
& -r_{u 1}=0.4, r_{u 2}=0.5 \\
& -r_{u 1}=0.8, r_{u 2}=0.9
\end{aligned}
$$

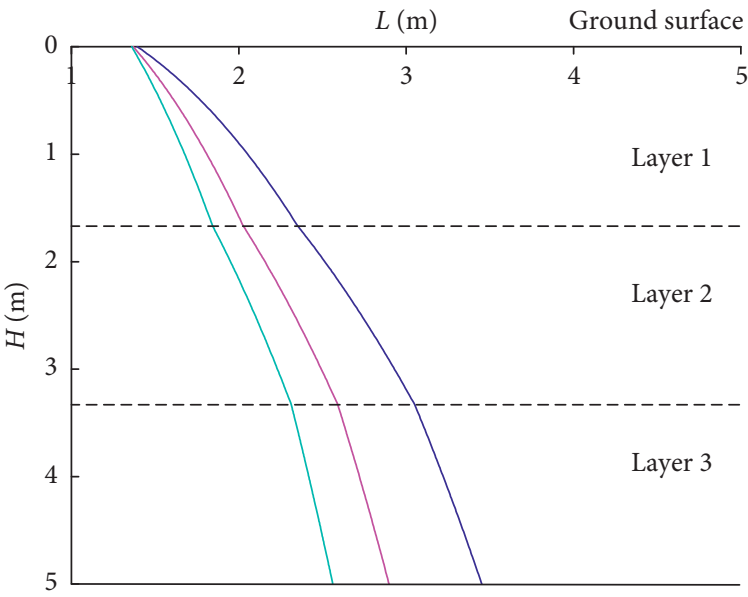

$$
\begin{aligned}
-r_{u 1} & =0, r_{u 2}=0.1 \\
-r_{u 1} & =0.4, r_{u 2}=0.5 \\
-r_{u 1} & =0.8, r_{u 2}=0.9
\end{aligned}
$$

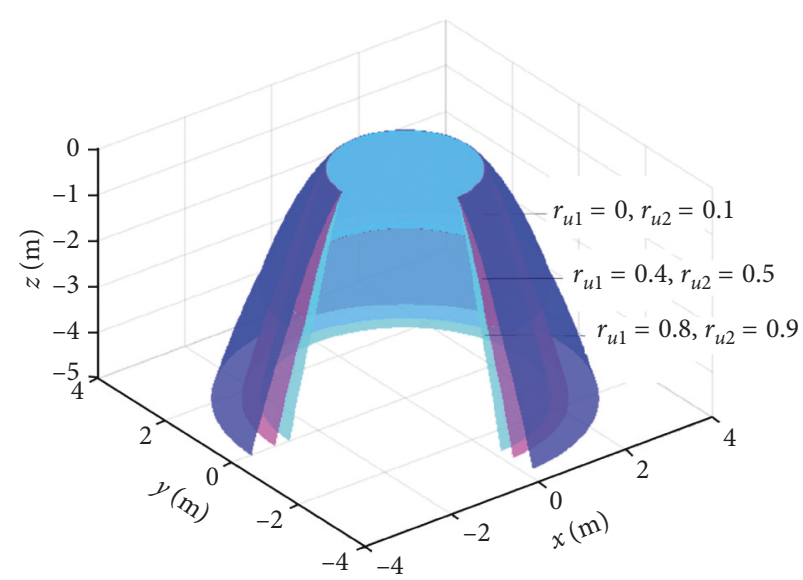

(a)

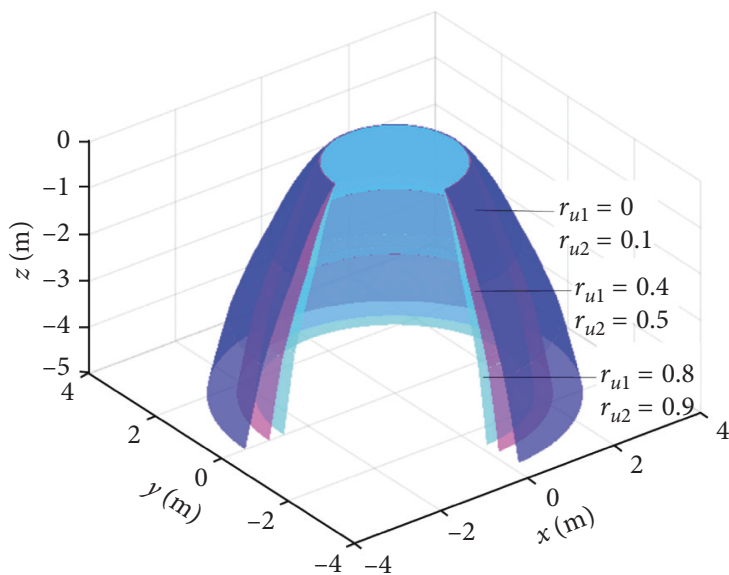

(b)

Figure 5: Continued. 

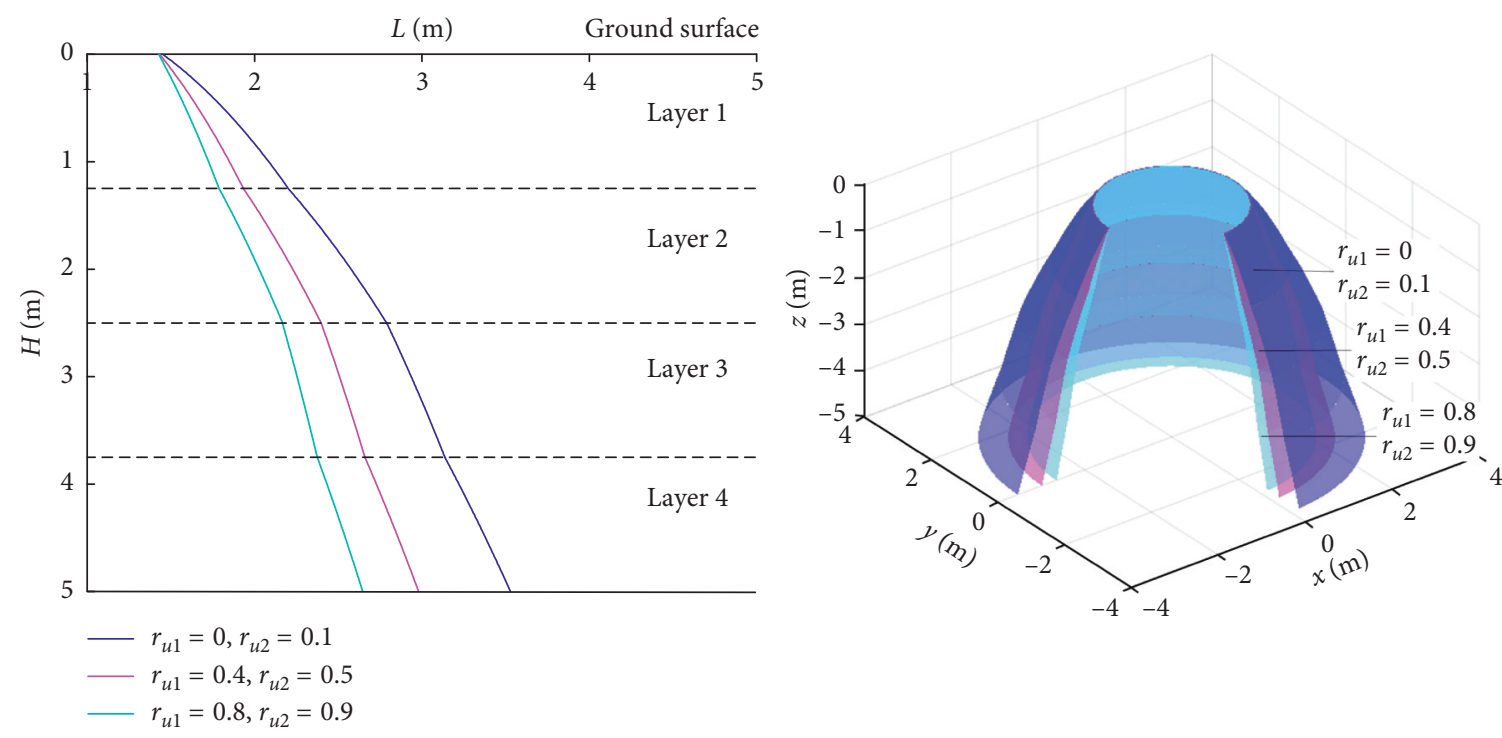

(c)
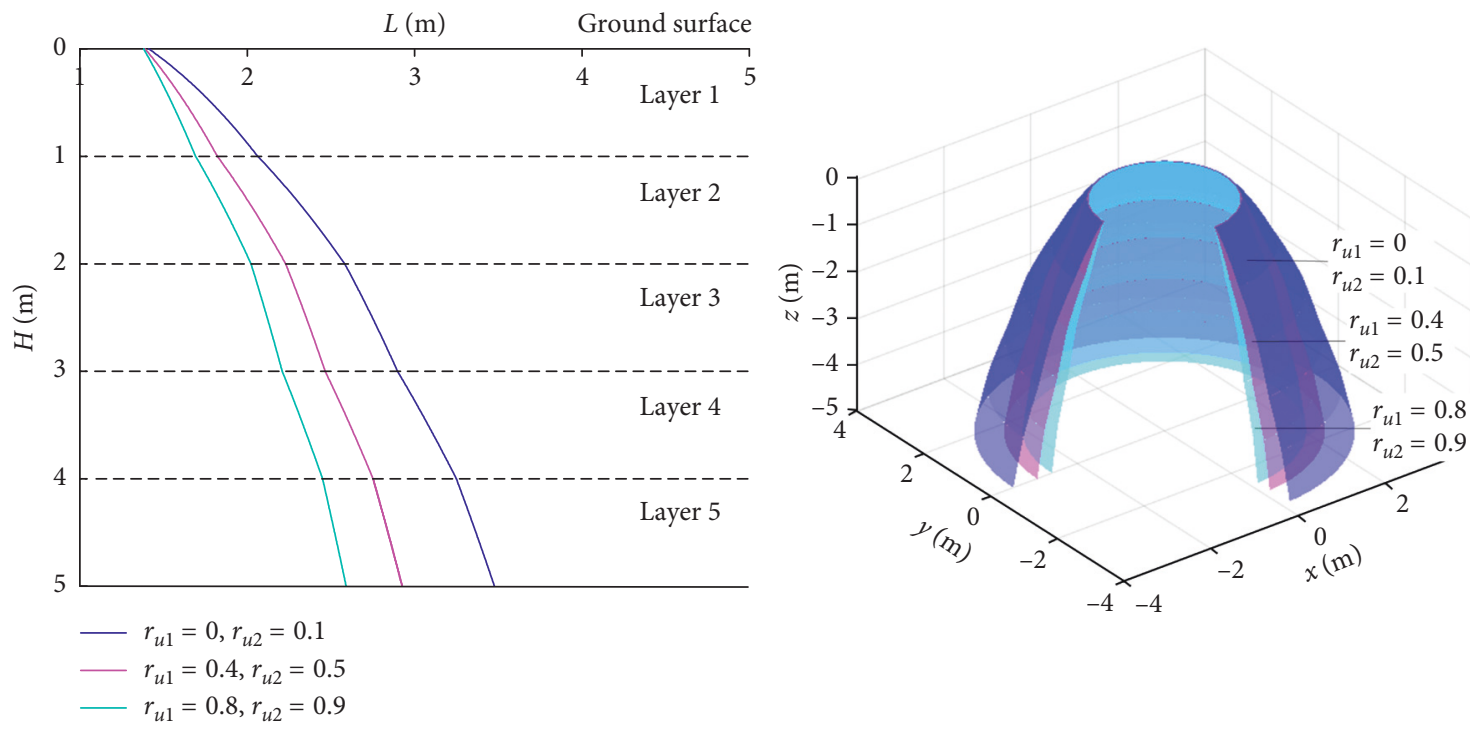

(d)

FiguRE 5: Collapse surfaces for varying roof stratification numbers and pore water pressure coefficients: (a) two layers; (b) three layers; (c) four layers; (d) five layers.

4.4. Effects of Soil Parameters, Support Pressure, and Ground Overload on the Collapse Area. In order to further analyze the effects of other parameters such as the soil strength parameters, support pressure, and ground overload on the collapse area, we selected a rectangular tunnel with two roof soil layers for discussion in this section. Accordingly, we obtain the collapse surfaces corresponding to these factors, as shown in Figure 7. Specifically, we set the parameters of the upper soil layer as follows: $c_{01}=20-40 \mathrm{kPa}$, $\sigma_{t 1}=40-60 \mathrm{kPa}, \gamma_{1}=15-21 \mathrm{kN} / \mathrm{m}^{3}$, and $m_{1}=1.6-2.6$, and those of the lower soil layer are set as follows: $c_{02}=30-50 \mathrm{kPa}, \quad \sigma_{t 2}=50-70 \mathrm{kPa}, \quad \gamma_{2}=17-23 \mathrm{kN} / \mathrm{m}^{3}$, and $m_{2}=1.4-2.4$. The support pressure ranges from $20-$ $40 \mathrm{kPa}$. The ground overload ranges from $300-500 \mathrm{kPa}$.

As can be seen from Figure 7, when other parameters remain constant, the collapse area of the tunnel roof increases with increasing cohesion and support pressure but decreases with increasing nonlinear coefficient, unit weight, and ground overload. Among them, the soil cohesion has the most significant influence on the collapse area. Moreover, the influence laws of varying parameters on the collapse area obtained in this paper are also consistent with the results of Yang and Yao [23].

4.5. Effects of Varying Parameters on the Weight of the Collapsed Soil Masses. The above shows that when we determine the collapse area above the tunnel, we can obtain the corresponding weight of the collapsed soil masses. In this section, we plot the influence curves of varying parameters on the weight of the collapsed soil masses when the tunnel burial depth ranges from $1 \mathrm{~m}$ to $6 \mathrm{~m}$, as shown in Figure 8. 


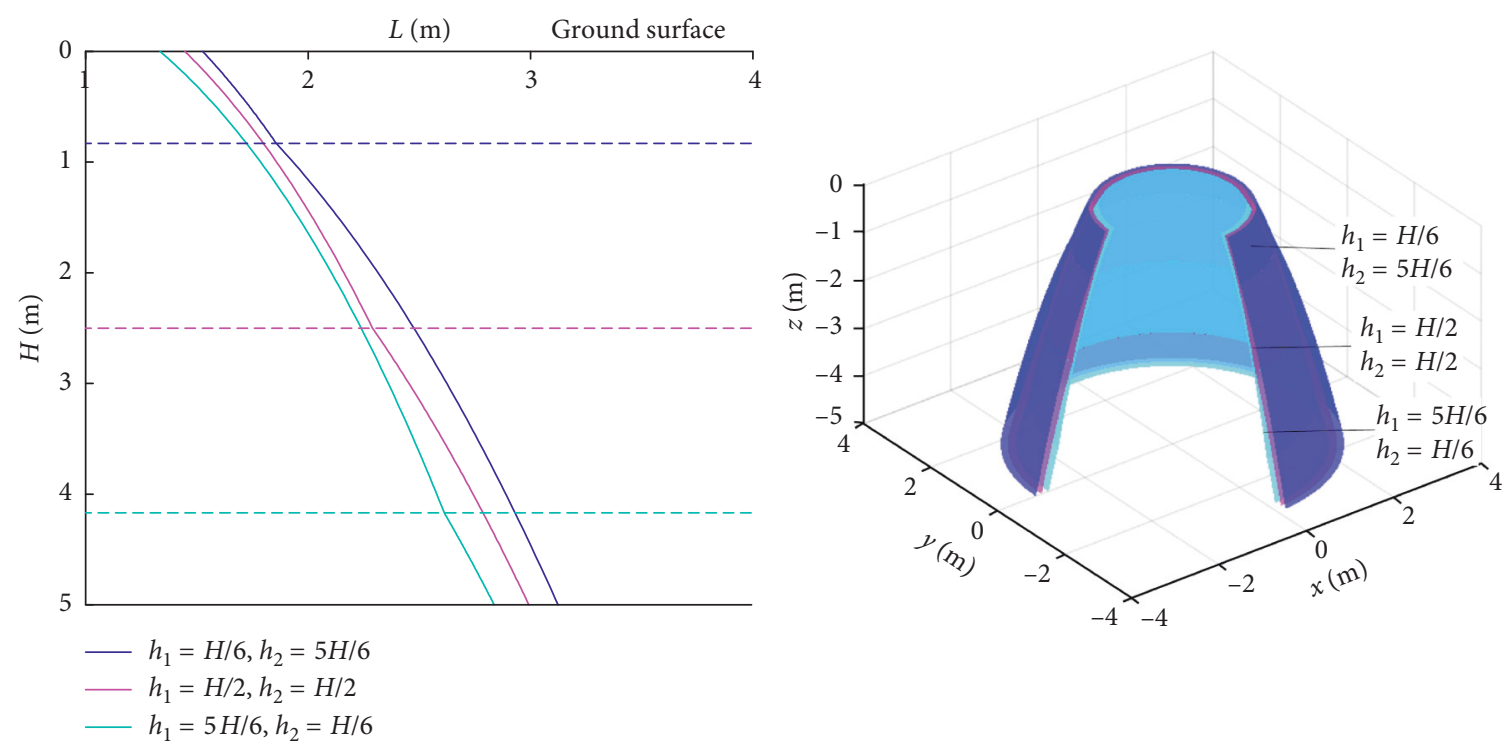

Figure 6: Collapse surfaces for varying thicknesses of soil layers.
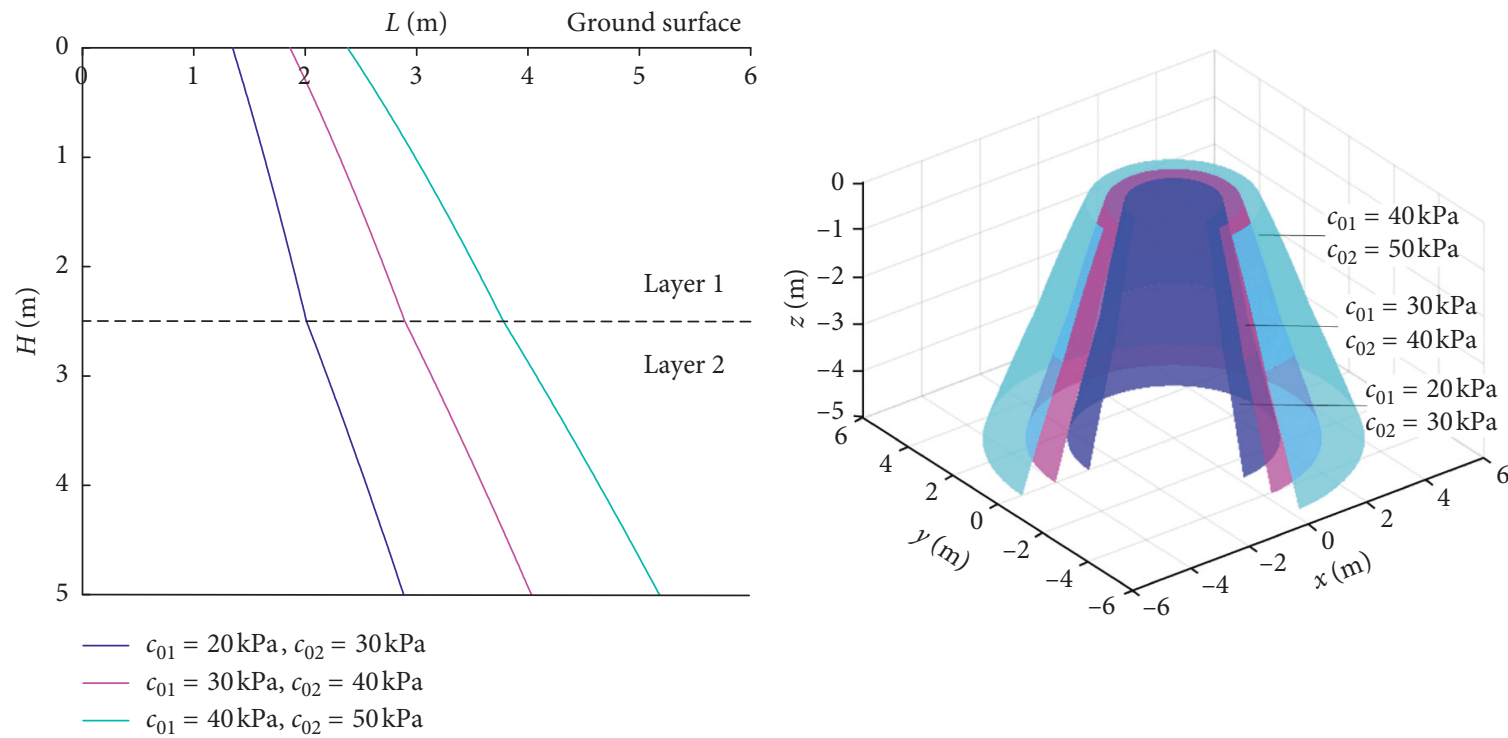

(a)

Figure 7: Continued. 

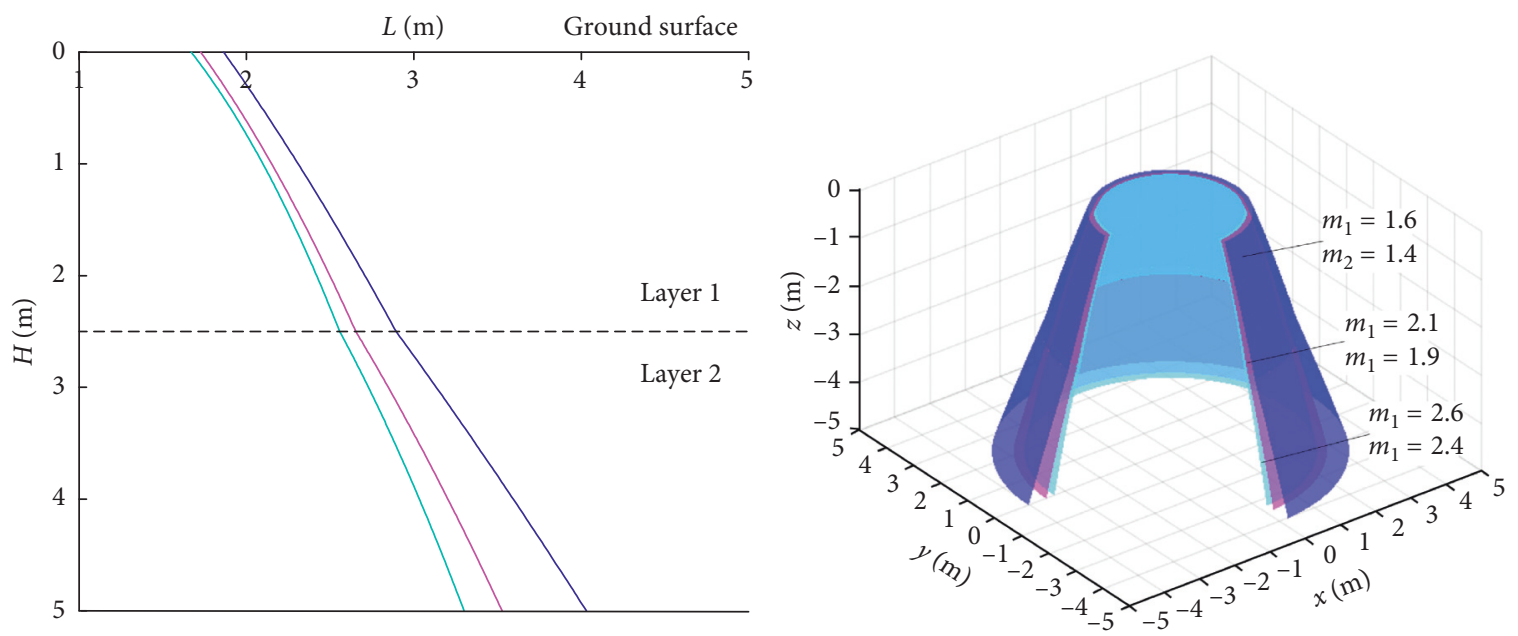

$-m_{1}=1.6, m_{2}=1.4$

- $m_{1}=2.1, m_{1}=1.9$

$-m_{1}=2.6, m_{1}=2.4$

(b)
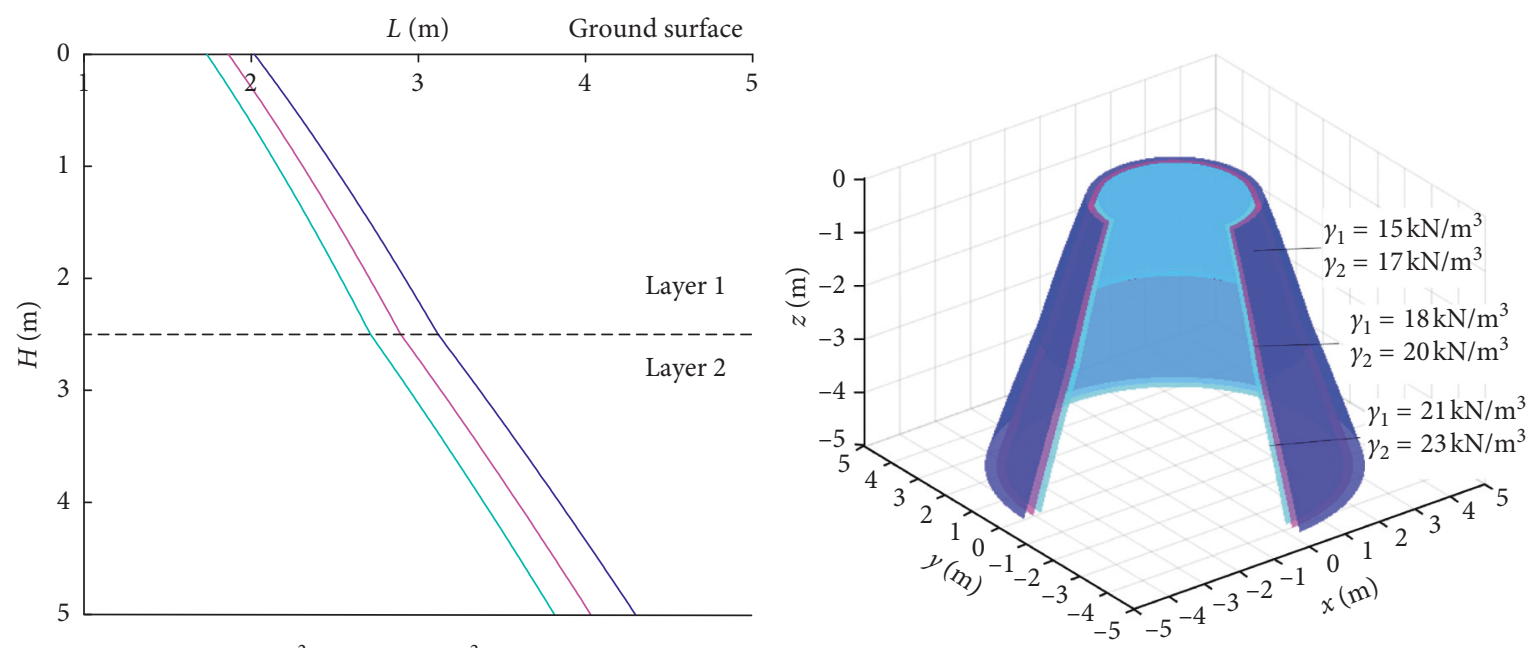

$-\gamma_{1}=15 \mathrm{kN} / \mathrm{m}^{3}, \gamma_{2}=17 \mathrm{kN} / \mathrm{m}^{3}$

$-\gamma_{1}=18 \mathrm{kN} / \mathrm{m}^{3}, \gamma_{2}=20 \mathrm{kN} / \mathrm{m}^{3}$

$\gamma_{1}=21 \mathrm{kN} / \mathrm{m}^{3}, \gamma_{2}=23 \mathrm{kN} / \mathrm{m}^{3}$

(c)
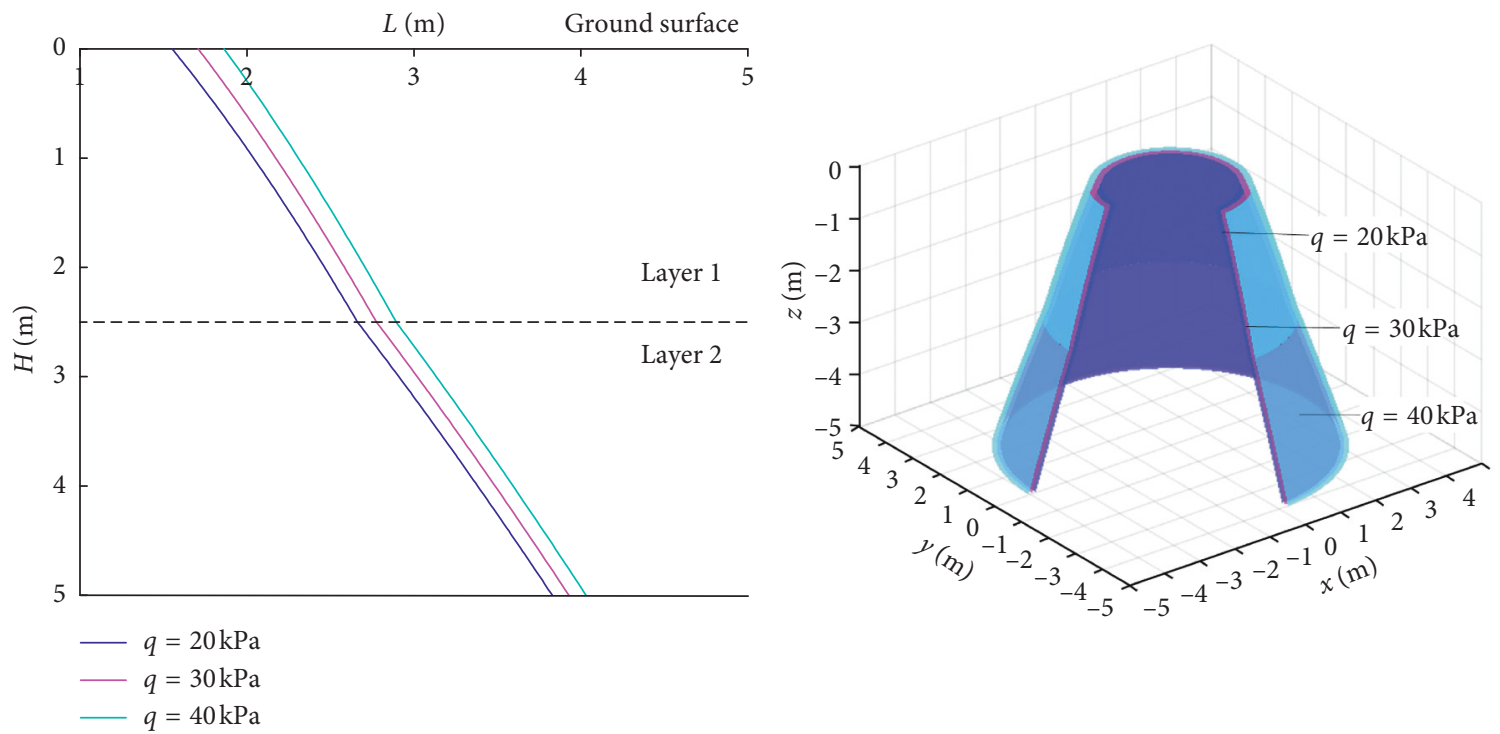

(d)

Figure 7: Continued. 


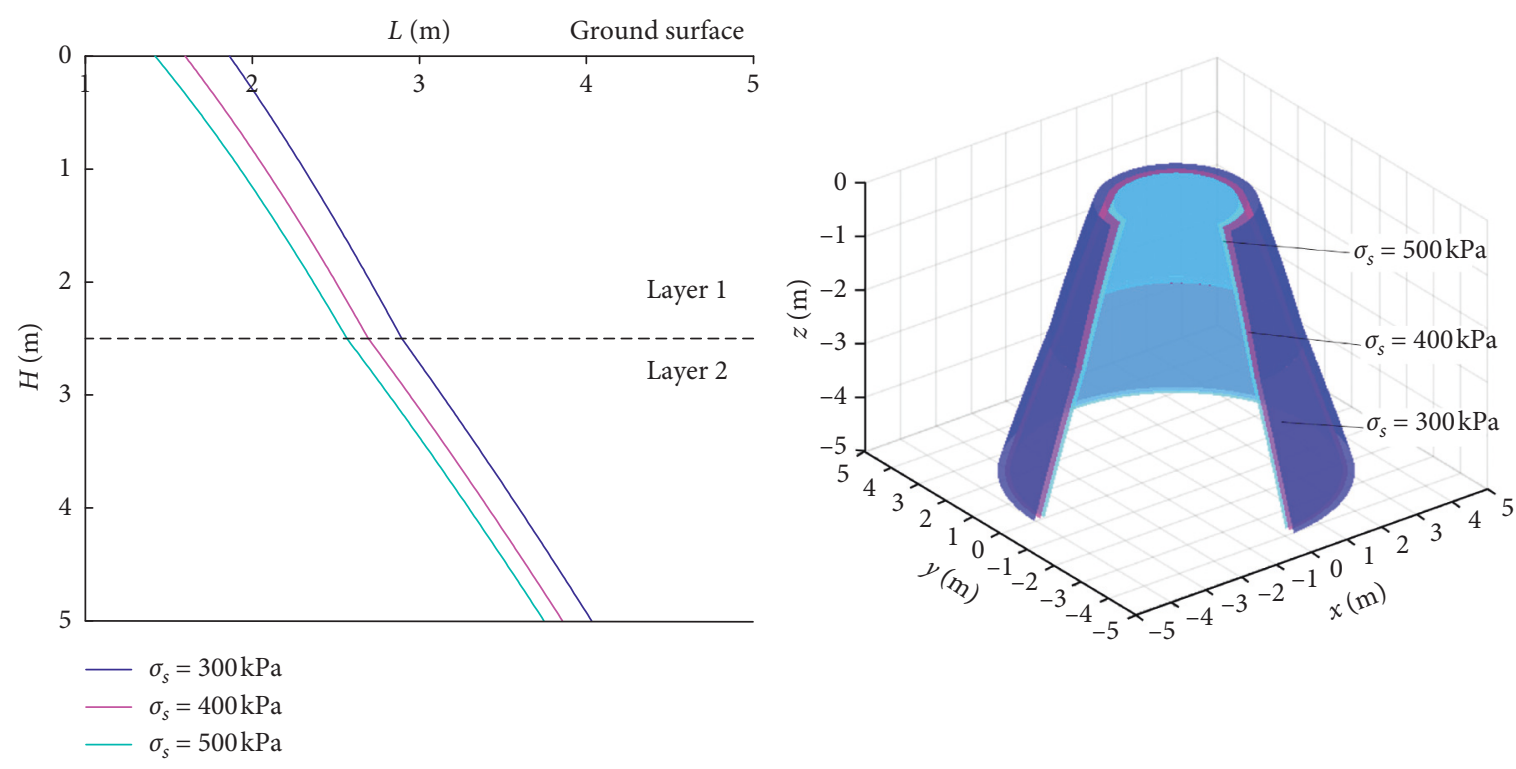

(e)

FIGURE 7: Collapse surfaces for varying other parameters: (a) cohesion; (b) nonlinear coefficient; (c) unit weight; (d) support pressure; (e) ground overload.

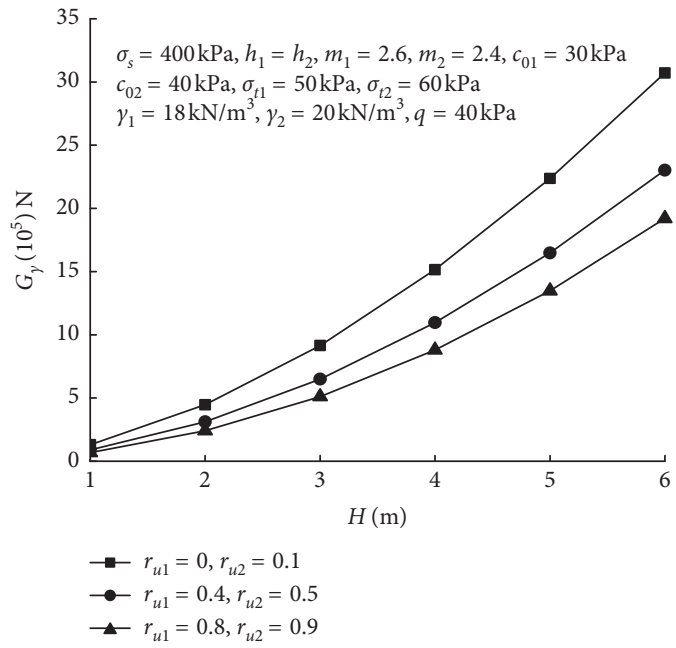

(a)

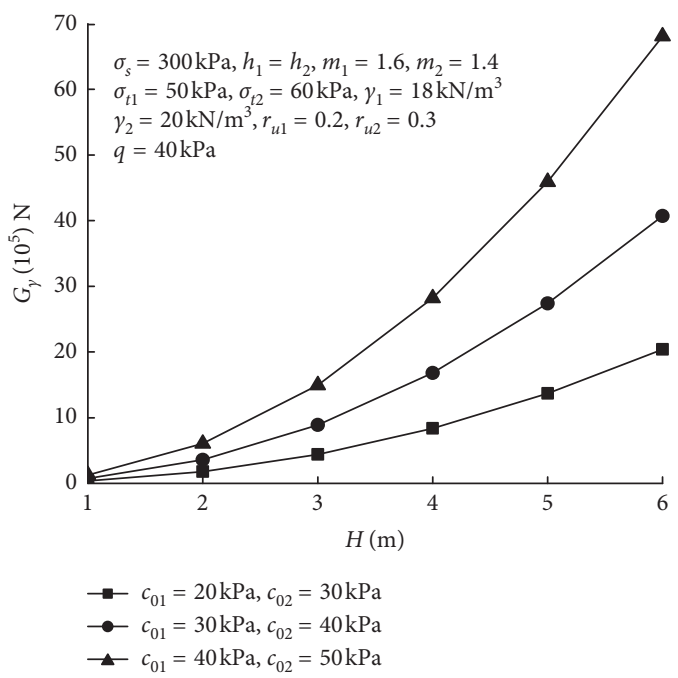

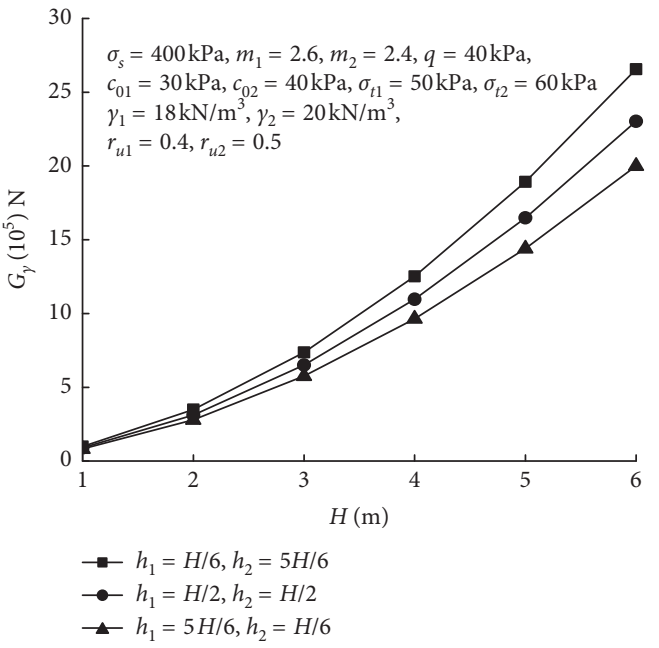

(b)

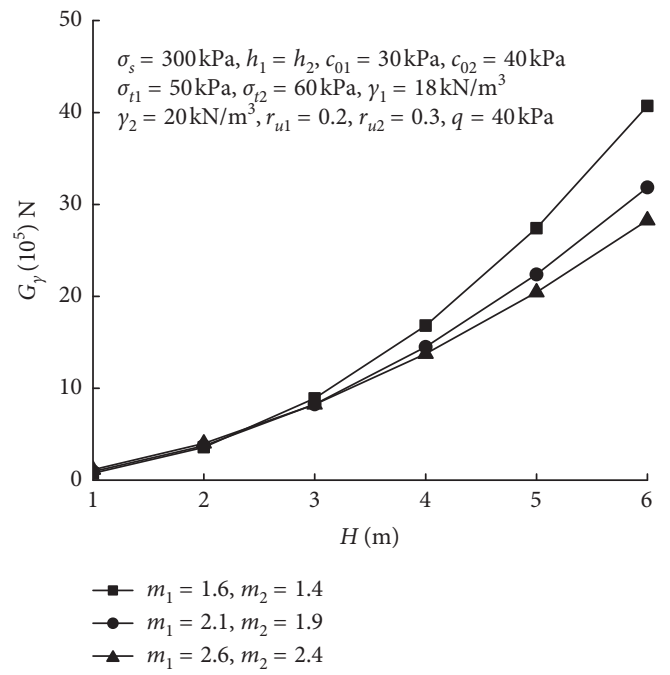

(d)

Figure 8: Continued. 


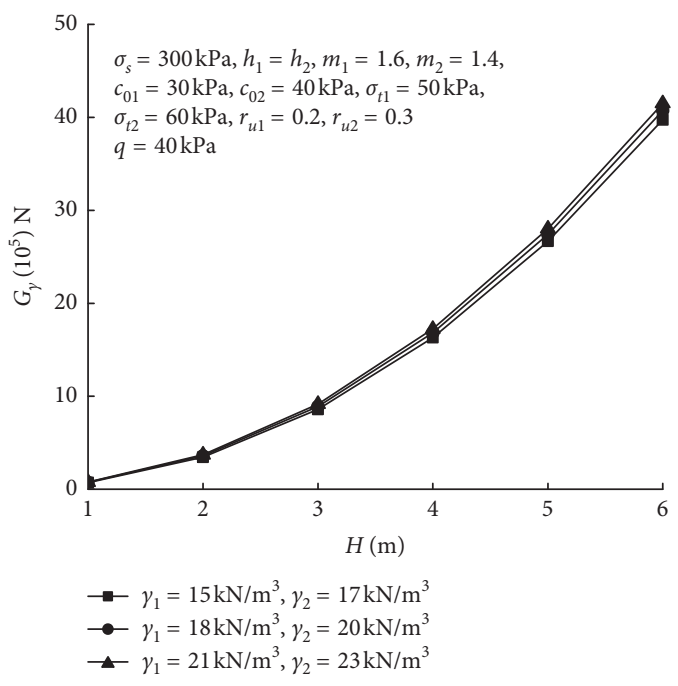

(e)

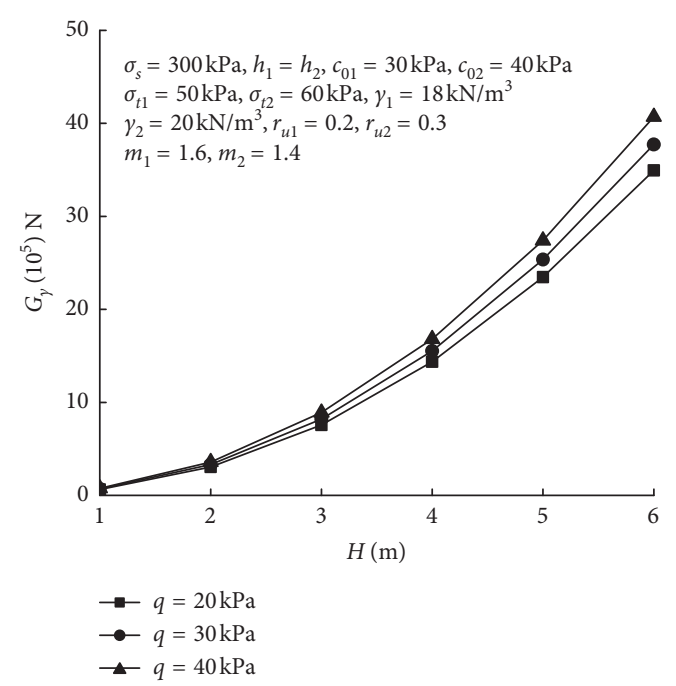

(f)

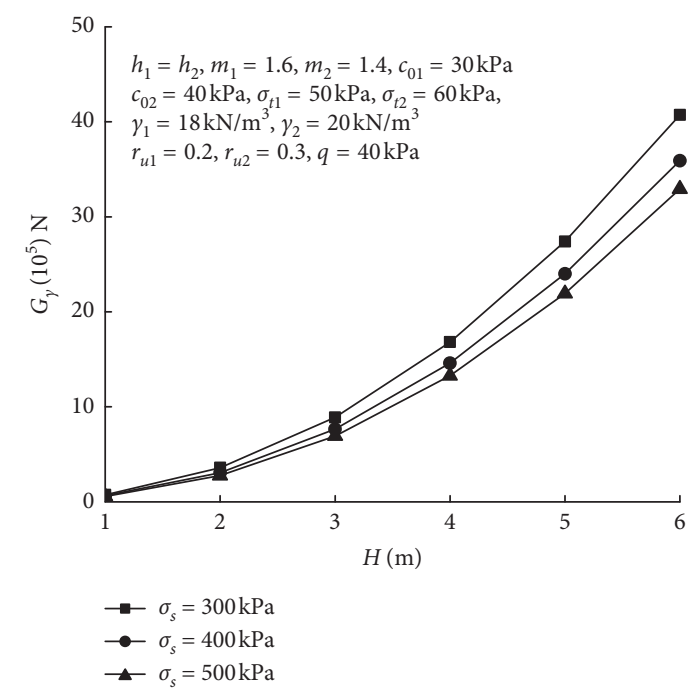

(g)

FiguRE 8: Weight of the collapsed soil masses with varying parameters: (a) pore water pressure coefficient; (b) layer thickness; (c) cohesion; (d) nonlinear coefficient; (e) unit weight; (f) support pressure; (g) ground overload.

The adopted parameters are consistent with those in Figures 5-7.

As can be seen from Figure 8, the weight of the collapsed soil masses increases with increasing tunnel burial depth. Especially when the burial depth is considerable, the collapse weight increases. When the burial depth is constant, the weight of the collapsed soil masses increases with increasing soil cohesion, unit weight, and support pressure, while it decreases with increasing thickness of the upper soil layer, pore water pressure coefficient, nonlinear coefficient, and ground overload. Among them, the soil cohesion has the most significant influence, which is consistent with the conclusion in Section 4.4. In particular, when the cohesion is large, the collapse weight increases significantly.

4.6. Suggestions for Engineering Design and Construction. Based on the above analysis results, we obtained the influence laws of the roof stratification, pore water pressure, soil parameters, support pressure, and ground overload on the area and weight of the collapsed soil masses. The magnitude of the collapse area, to a certain extent, reflects the safety state of the tunnel roof. To ensure the safety of shallow soil tunnels in layered strata, we provide the following suggestions for engineering design and construction:

(1) The effects of the roof stratification and pore water pressure should be incorporated into the design of tunnel support, especially when the tunnels pass through layered strata or groundwater-developed strata. Only in this way, the support design for shallow soil tunnels may be more approximate to the practice.

(2) The soil cohesion is also a significant factor affecting tunnel collapse. The techniques such as advanced pipe grouting, bolt grouting, and others can be employed to reinforce the stratum and enhance the soil strength. 
Meanwhile, in the grouting process, the pore water pressure within the strata can also be effectively reduced. Thus, the grouting techniques are an effective way to improve the stability of shallow soil tunnels.

(3) In order to reduce the disadvantageous effect of the ground overload, all kinds of construction facilities on the ground surface should be removed in good time. Also, the vibration effect of the ground traffic on tunnel structures should be suppressed as far as possible.

(4) For the shallow soil tunnels, the roof is a crucial position of deformation and failure, and the design of tunnel support should pay particular attention to it. Specifically, the roof support parameters should be reasonably optimized to ensure that the roof has sufficient supporting strength. Then, the collapse accidents could be effectively avoided.

\section{Conclusions}

(1) Based on the upper bound theorem, we constructed a three-dimensional axisymmetric mechanism for the failure of the soil masses above a shallow soil tunnel in layered strata. Utilizing a nonlinear failure criterion derives the analytical solutions of the weight of the collapsed soil masses and the corresponding collapse surfaces. Furthermore, we obtained the influence laws of varying parameters on the collapse area and weight. We provide some suggestions for engineering design and construction. The results are consistent with the existing research and numerical simulation results, which verifies the validity of the proposed method and provides some theoretical guidance for support design and construction of shallow soil tunnels in layered strata.

(2) The roof stratification and pore water pressure have a significant impact on the area and weight of the collapsed soil masses, which should not be neglected in engineering design. Specifically, the collapse area and weight tend to decrease continuously with increasing thickness of the upper soil layer and pore water pressure coefficient.

(3) As the soil cohesion and support pressure increase, the area and weight of the collapsed soil masses increase gradually but decrease with increasing nonlinear coefficient and ground overload. Among them, the cohesion and nonlinear coefficient have a significant impact, which should be given special consideration in engineering design.

\section{Data Availability}

The data used to support the findings of this study are included within the article.

\section{Conflicts of Interest}

The authors declare that there are no conflicts of interest regarding the publication of this paper.

\section{Acknowledgments}

The authors also would like to acknowledge the financial support from the National Natural Science Foundation of China (nos. 51704177 and 51809159), a project of Shandong Province Higher Educational Science and Technology Program (J16LG04), Shandong Co-Innovation Center for Disaster Prevention and Mitigation of Civil Structures (XTP201911), and the Doctoral Research Fund of Shandong Jianzhu University (XNBS1501).

\section{References}

[1] P. Chambon and J. F. Corté, "Shallow tunnels in cohesionless soil: stability of tunnel face," Journal of Geotechnical Engineering, vol. 120, no. 7, pp. 1148-1165, 1994.

[2] Y. X. Wu, Research on Influence Laws of Ground Surface Settlement Caused by Qingdao Subway Construction on Buildings and its Prevention, Qingdao Technological University, Qingdao, China, 2012.

[3] E. Leca and L. Dormieux, "Upper and lower bound solutions for the face stability of shallow circular tunnels in frictional material," Géotechnique, vol. 40, no. 4, pp. 581-606, 1990.

[4] I.-M. Lee, S.-W. Nam, and J.-H. Ahn, "Effect of seepage forces on tunnel face stability," Canadian Geotechnical Journal, vol. 40, no. 2, pp. 342-350, 2003.

[5] C. E. Augarde, A. V. Lyamin, and S. W. Sloan, "Stability of an undrained plane strain heading revisited," Computers and Geotechnics, vol. 30, no. 5, pp. 419-430, 2003.

[6] C. Zhang, K. Han, and D. Zhang, "Face stability analysis of shallow circular tunnels in cohesive-frictional soils," Tunnelling and Underground Space Technology, vol. 50, pp. 345357, 2015.

[7] N. Khezri, H. Mohamad, M. HajiHassani, and B. Fatahi, "The stability of shallow circular tunnels in soil considering variations in cohesion with depth," Tunnelling and Underground Space Technology, vol. 49, pp. 230-240, 2015.

[8] M. Fraldi and F. Guarracino, "Limit analysis of collapse mechanisms in cavities and tunnels according to the HoekBrown failure criterion," International Journal of Rock Mechanics and Mining Sciences, vol. 46, no. 4, pp. 665-673, 2009.

[9] M. Fraldi and F. Guarracino, "Analytical solutions for collapse mechanisms in tunnels with arbitrary cross sections," International Journal of Solids and Structures, vol. 47, no. 2, pp. 216-223, 2010.

[10] M. Fraldi, R. Cavuoto, A. Cutolo, and F. Guarracino, "Stability of tunnels according to depth and variability of rock mass parameters," International Journal of Rock Mechanics and Mining Sciences, vol. 119, pp. 222-229, 2019.

[11] X. L. Yang and F. Huang, "Collapse mechanism of shallow tunnel based on nonlinear Hoek-Brown failure criterion," Tunnelling and Underground Space Technology, vol. 26, no. 6, pp. 686-691, 2011.

[12] X. L. Yang and K. F. Li, "Roof collapse of shallow tunnel in layered Hoek-Brown rock media," Geomechanics and Engineering, vol. 11, no. 6, pp. 867-877, 2016.

[13] F. Huang, X.-l. Yang, and L.-h. Zhao, "Upper bound solution of supporting pressure for a shallow square tunnel based on the Hoek-Brown failure criterion," Journal of Zhejiang University-Science A, vol. 13, no. 4, pp. 284-292, 2012.

[14] F. Huang and X. L. Yang, "Upper bound limit analysis of collapse shape for circular tunnel subjected to pore pressure based on the Hoek-Brown failure criterion," Tunnelling and 
Underground Space Technology, vol. 26, no. 5, pp. 614-618, 2011.

[15] C.-p. Zhang, K.-h. Han, Q. Fang, and D.-l. Zhang, "Functional catastrophe analysis of collapse mechanisms for deep tunnels based on the Hoek-Brown failure criterion," Journal of Zhejiang University-Science A, vol. 15, no. 9, pp. 723-731, 2014.

[16] H. T. Wang, L. G. Wang, S. C. Li, Q. Wang, P. Liu, and X. J. Li, "Roof collapse mechanisms for a shallow tunnel in two-layer rock strata incorporating the influence of groundwater," Engineering Failure Analysis, vol. 98, pp. 215-227, 2019.

[17] C. Lyu and Z. Zeng, "Upper bound limit analysis of unsymmetrical progressive collapse of shallow tunnels in inclined rock stratum," Computers and Geotechnics, vol. 116, Article ID 103199, 2019.

[18] X. L. Yang and F. Huang, "Three-dimensional failure mechanism of a rectangular cavity in a Hoek-Brown rock medium," International Journal of Rock Mechanics and Mining Sciences, vol. 61, pp. 189-195, 2013.

[19] F. Huang, X. L. Yang, and T. H. Ling, "Prediction of collapsing region above deep spherical cavity roof under axis-symmetrical conditions," Rock Mechanics and Rock Engineering, vol. 47, no. 4, pp. 1511-1516, 2014.

[20] C.-b. Qin, Z.-b. Sun, and Q. Liang, "Limit analysis of roof collapse in tunnels under seepage forces condition with threedimensional failure mechanism," Journal of Central South University, vol. 20, no. 8, pp. 2314-2322, 2013.

[21] A.-H. Soubra, D. Dias, F. Emeriault, and R. Kastner, "Threedimensional face stability analysis of circular tunnels by a kinematical approach," in Proceedings of the GeoCongress, Characterization, Monitoring and Modelling of Geosystems, pp. 9-12, New Orleans, LA, USA, March 2008.

[22] K. Guan, W. C. Zhu, L. L. Niu, and Q. Y. Wang, "Threedimensional upper bound limit analysis of supported cavity roof with arbitrary profile in Hoek-Brown rock mass," Tunnelling and Underground Space Technology, vol. 69, pp. 147-154, 2017.

[23] X. L. Yang and C. Yao, "Axisymmetric failure mechanism of a deep cavity in layered soils subjected to pore pressure," International Journal of Geomechanics, vol. 17, no. 8, Article ID 04017031, 2017.

[24] X. L. Yang and C. Yao, "Stability of tunnel roof in nonhomogeneous soils," International Journal of Geomechanics, vol. 18, no. 3, Article ID 06018002, 2018.

[25] X. L. Yang, T. Zhou, and W. T. Li, "Reliability analysis of tunnel roof in layered Hoek-Brown rock masses," Computers and Geotechnics, vol. 104, pp. 302-309, 2018.

[26] C. B. Qin, X. L. Yang, Q. J. Pan, Z. B. Sun, L. L. Wang, and T. Miao, "Upper bound analysis of progressive failure mechanism of tunnel roofs in partly weathered stratified Hoek-Brown rock masses," International Journal of Rock Mechanics and Mining Sciences, vol. 74, pp. 157-162, 2015.

[27] C. Qin and S. C. Chian, "2D and 3D stability analysis of tunnel roof collapse in stratified rock: a kinematic approach," International Journal of Rock Mechanics and Mining Sciences, vol. 100, pp. 269-277, 2017.

[28] C. B. Qin, S. C. Chian, and X. L. Yang, "3D limit analysis of progressive collapse in partly weathered Hoek-Brown rock banks," International Journal of Geomechanics, vol. 17, no. 7, Article ID 04017011, 2017.

[29] C. Qin and S. C. Chian, "Revisiting crown stability of tunnels deeply buried in non-uniform rock surrounds," Tunnelling and Underground Space Technology, vol. 73, pp. 154-161, 2018.
[30] E. Hoek, "Strength of jointed rock masses," Géotechnique, vol. 33, no. 3, pp. 187-223, 1983.

[31] J. G. Agar, N. R. Morgenstern, and J. D. Scott, "Shear strength and stress-strain behaviour of Athabasca oil sand at elevated temperatures and pressures," Canadian Geotechnical Journal, vol. 24, no. 1, pp. 1-10, 1987.

[32] F. J. Santarelli, Theoretical and Experimental Investigation of the Stability of the Axisymmetric Borehole, University of London, London, UK, 1987.

[33] X. L. Yang, Limit Analysis Method and Application to Geotechnical Engineering with Linear and Nonlinear Failure Criteria, Central South University, Changsha, China, 2002.

[34] C. Viratjandr and R. L. Michalowski, "Limit analysis of submerged slopes subjected to water drawdown," Canadian Geotechnical Journal, vol. 43, no. 8, pp. 802-814, 2006.

[35] W. F. Chen, Limit Analysis and Soil Plasticity, Elsevier, Amsterdam, Netherlands, 1975.

[36] X. Y. Zhang, Geotechnical Plastic Mechanics, China Communications Press Co., Ltd., Beijing, China, 1993. 


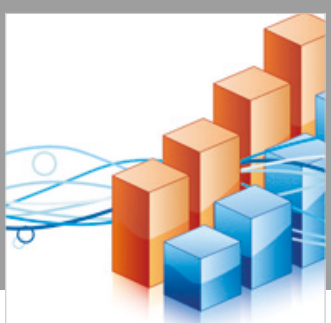

Advances in

Operations Research

\section{-n-m}
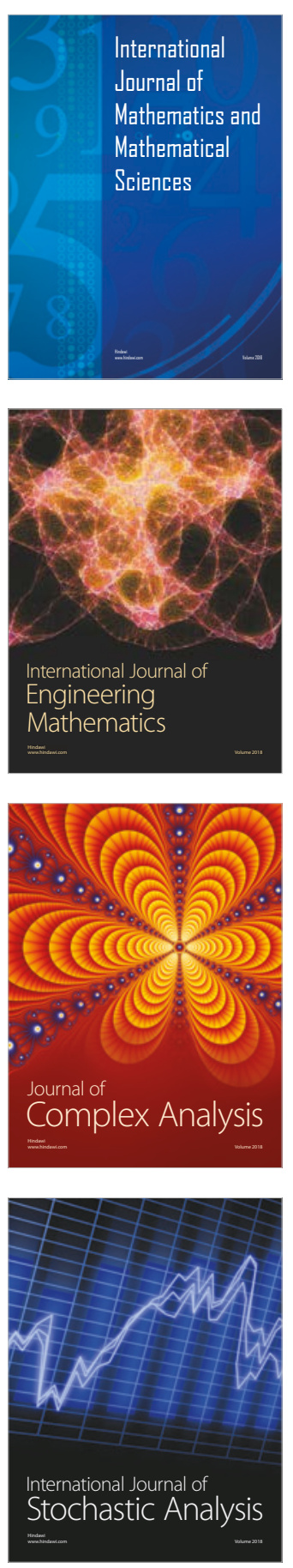
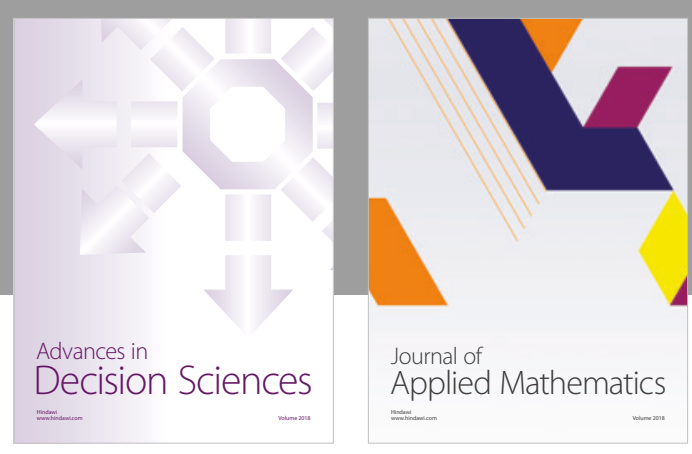

Journal of

Applied Mathematics
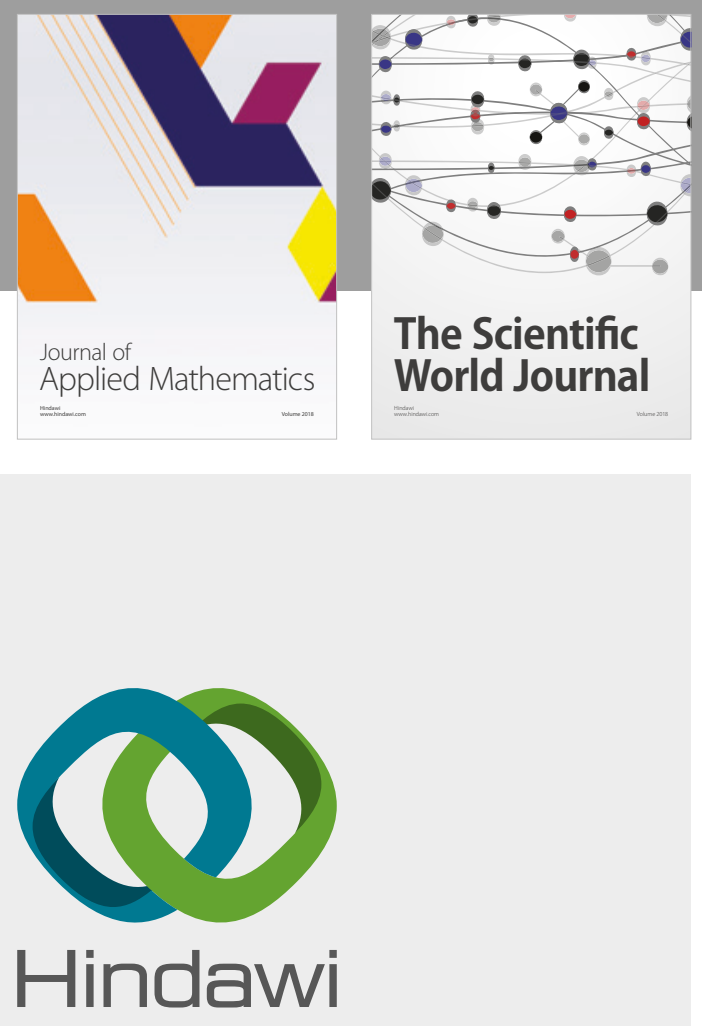

Submit your manuscripts at

www.hindawi.com

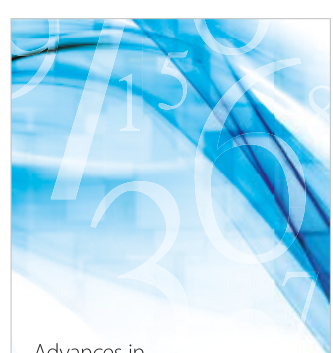

Advances in
Numerical Analysis
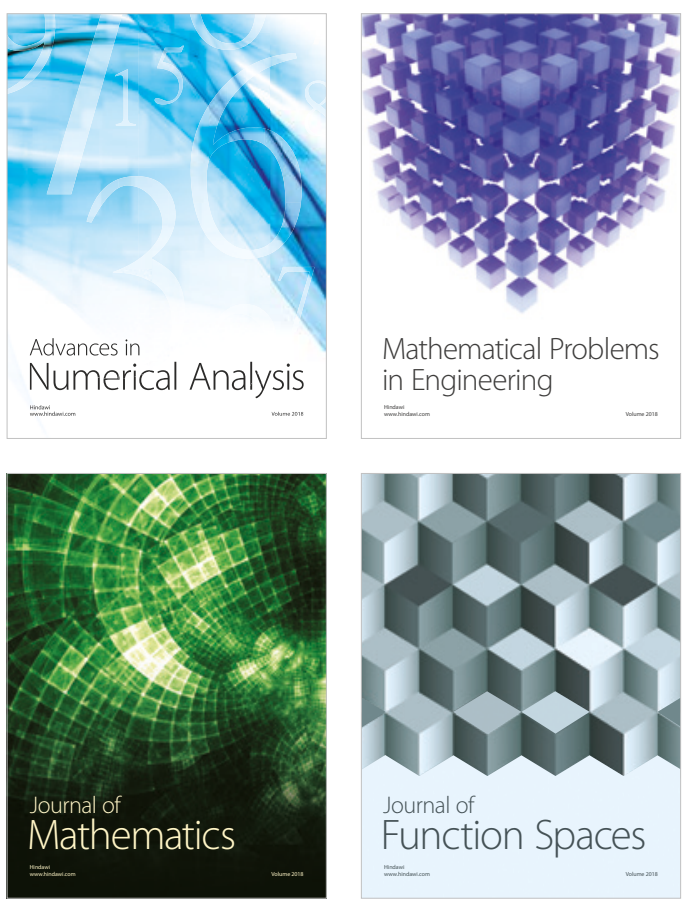

Mathematical Problems in Engineering

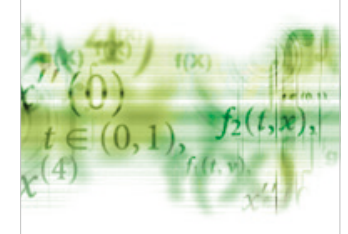

International Journal of

Differential Equations

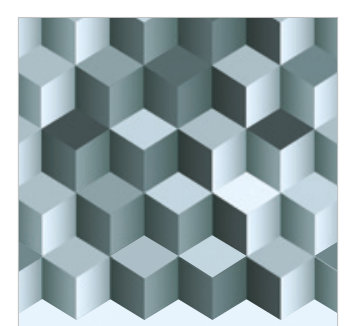

Journal of

Function Spaces

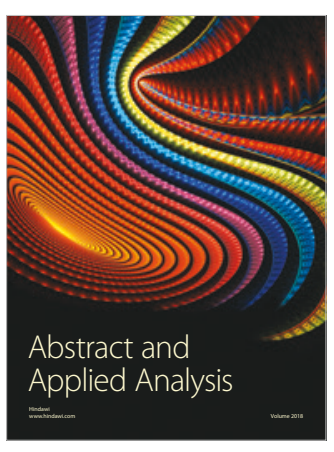

The Scientific

World Journal

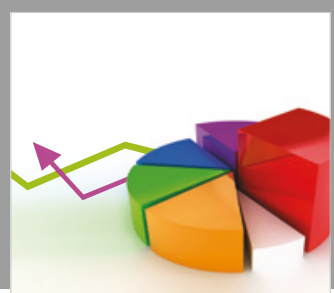

Journal of

Probability and Statistics
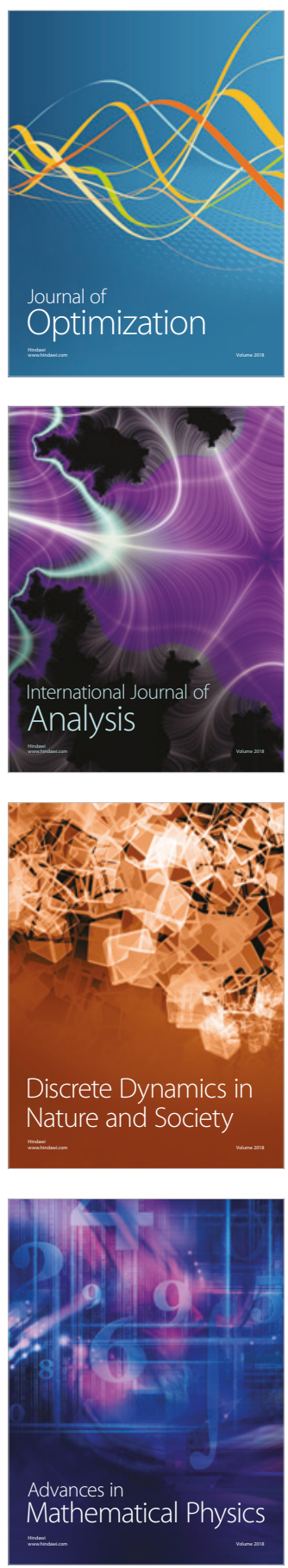